\title{
SDU\%
}

\section{The Origins of Creativity: The Case of the Arts in the United States since 1850}

by

Karol Jan Borowiecki

Discussion Papers on Business and Economics

No. $11 / 2019$

FURTHER INFORMATION Department of Business and Economics Faculty of Business and Social Sciences University of Southern Denmark Campusvej 55, DK-5230 Odense M 


\title{
The Origins of Creativity: The Case of the Arts in the United States since 1850
}

\author{
Karol Jan Borowiecki*1 \\ ${ }^{1}$ Historical Economics and Development Group (HEDG), \\ Department of Business and Economics, University of Southern \\ Denmark \\ ${ }^{1}$ Department of Economics, Trinity College Dublin
}

September 17, 2019

\begin{abstract}
This research illuminates the historical development of creative activity in the United States. Census data is used to identify creative occupations (i.e., artists, musicians, authors, actors) and data on prominent creatives, as listed in a comprehensive biographical compendium. The analysis first sheds light on the socio-economic background of creative people and how it has changed since 1850 . The results indicate that the proportion of female creatives is relatively high, time constraints can be a hindrance for taking up a creative occupation, racial inequality is present and tends to change only slowly, and access to financial resources within a family facilitates the uptake of an artistic occupation. Second, the study systematically documents and quantifies the geography of creative clusters in the United States and explains how these have evolved over time and across creative domains. Third, it investigates the importance of outstanding talent in a discipline for the local growth of an artistic cluster.
\end{abstract}

Keywords: Creativity, artists, geographic clustering, agglomeration economies, urban history.

JEL Classification Numbers: R1, N33, Z11.

\footnotetext{
*Corresponding author: kjb@sam.sdu.dk. The author wishes to thank Philipp Ager, David de la Croix, Walker Hanlon, Nathan Nunn, Casper Worm Hansen, and participants at the World Economic History Congress (Kyoto), Interdisciplinary Conference on Art Markets (Amsterdam), Workshop on Growth, History and Development (Odense), Economic History and Economic Policy Conference (Paris), FRESH Meeting (Odense), European Workshop on Applied Cultural Economics (Vienna), SOUND Economic History Workshop (Lund) and invited seminar at Syddansk Universitet Sønderborg for helpful consultations and insightful comments.
} 
"When I say artist I mean the one who is building things... some with a brush some with a shovel - some choose a pen." Jackson Pollock

\section{Introduction}

Throughout history the careers of artists have been affected by various economic forces, such as shifts of art demand (Galenson and Weinberg, 2000). These demand shifts have caused not only radical changes in the careers of successful practitioners, but they illustrate also how the taste of the American art consumer matured over time. The underlying study continues the exploration of a society's taste and art demand by extending the approach to a wider population of artists and additional artistic domains, and by covering a period of one and a half centuries. By doing so, we come close to documenting the emergence of artistic creativity.

Historical population growth in the United States was fast, reaching 23 million in 1850, 76 million in 1900, 151 million in 1950, and 309 million in 2010. Economic growth in terms of overall GDP was equally rapid and the resulting wealth increases benefited the whole society. This coincided with the emergence of a relatively rich group of geographically concentrated people who patronized the arts and supported the construction of concert halls, art galleries, and other types of cultural infrastructure, as well as the less rich who are willing to pay taxes to support art teachers in schools. Along with rising income and improving education, the demand for art and culture shifted over the course of the late 19th and 20th centuries. The change has been visible in numerous dimensions and in the exploration that follows I will document in particular a rapid increase in the number of artists and the rise in the diversity of artistic occupations.

The presence of creative people, in particular of artists, may be conducive to economic development (e.g., Florida, 2002) and is correlated with city growth (Ger- 
gaud et al., 2016). Creative and arts sectors are seen as "the key ingredient for job creation, innovation and trade" (UNCTAD, 2010) and are believed to constitute opportunities for developing countries to leapfrog into emerging high-growth areas of the world economy. Creativity is "driving the economy, reshaping entire industries and stimulating inclusive growth" (OECD, 2014). As can be seen in Figure 1, the correlation between the density of creative people and startup activity in US cities is surprisingly strong, also in the long run. ${ }^{1}$ Finally, artistic creativity is needed to produce cultural goods and services, and the advantages of having a wealthy cultural supply and a meaningful cultural heritage nowadays are vast and non-negligible, ranging from economic gains from tourism inflows to non-monetary gains arising from a common identity.

\section{Insert Figure 1 here}

Despite the remarkable importance of artistic creativity, economists have largely refrained from studying it. Creativity in the arts is explored even less by economic historians, especially since creativity is not a characteristic that has been priced highly on labor markets throughout most of history. In the past, employers have valued disciplined and hard-working workers (Crafts, 1985), as opposed to creative ones. Here by studying the case of the arts, which incorporate some of the earliest creative occupations, unique insights on the long-term development, geographic spread, and individual motivations to engage in creative activity can be explored. ${ }^{2}$

This research is mostly descriptive and does not support any causal claims. Nonetheless, it makes three main contributions. First, the rich individual-level data are used

\footnotetext{
${ }^{1}$ Even if simple scatter plots are subject to biases due to unobservable factors (e.g., educational attainment), the strength of the disclosed correlation is rather striking. Causal claims cannot be made, but recent research (e.g., Falck et al., 2015) shows that cultural amenities - which are likely related with the density of creatives - are an important factor in the location decision of high-skilled workers.

${ }^{2}$ In the remaining of the paper by referring to creativity or creative people, what is meant is artistic creativity and artists, albeit artistic creativity is likely correlated with the same variables as is the sort of creativity that leads to innovation in production and economic growth. For example, within psychology, artistic, scientific or entrepreneurial creativity is studied along side each other (e.g., Ludwig, 1995), albeit in different contexts.
} 
to shed light on the determinants of a person engaging in an artistic occupation. These analyses illuminate how the socio-economic profiles of artists have changed since 1850, thereby delivering unique insights into long-term patterns of artistic occupational choices. The focus is directed on individuals representing the visual arts, literary arts and performing arts, and music. The chosen categories are in line with the definition of traditional high art by Heilbrun and Gray (2001). Furthermore, by covering various types of creatives the data are suitable for identifying differences across artistic domains. Previously, the focus of economic history research has been directed at small samples of established artists, as these are typically observable today (e.g., Graddy, 2013; O'Hagan and Hellmanzik, 2008; Etro and Pagani, 2012; ?). In the underlying study, by employing of census data, the focus can be directed at the average artists instead.

The second contribution of the paper is the exploration of the dynamics associated with the historical development of US creative clusters. These investigations document and quantify the importance of specific geographic locations (cities) by including the census data along with data covering famous creatives who worked in the United States, as listed in the comprehensive biographical compendium - the Index Bio-bibliographicus Notorum Hominum (IBN). This allows important insights into the differences in the place and intensity of clustering between prominent and average creatives. Furthermore, it is possible to highlight differences in the geography across creative domains.

While the importance of certain cities within specific artistic domains is established, little is known about the clustering intensity and interrelations across different domains. Previous research, by applying heterogeneous samples, different data sources and different time periods covered, is not suitable to measure the relative importance and interplay across creative domains. Are some cities simply more cultured and attract artists from a range of different domains, or are there rather some forces in 
play that lead to specialization of artistic talent? This important question is not sufficiently well answered in the existing literature, and yet it is of relevance to our understanding of the clustering of creative activity and the benefits associated with agglomeration economies.

The third contribution is an analysis of how important artists affect local creative activity. In particular, it is explored how the presence of famous artists in a place are related to the probability of an individual becoming involved in a creative occupation. By making use of census data that reflect the creative involvement of average individuals, as opposed to prominent ones, it is possible to overcome the extreme non-random sample selection biases encountered in the fast growing related literature (e.g., O’Hagan and Borowiecki, 2010).

\section{Literature Review}

This research primarily relates to three strands of the literature. First, it connects with research on the works and lives of artists. Influential overviews of artists' labor markets and research thereof are presented by Benhamou (2011) and Alper and Wassal (2006). Graddy (2013) explores the accuracy and persistency of rankings of famous artists conducted by the 17th century art critic Roger de Piles. Etro and Pagani (2012) study contracts between patrons and successful artists in the 17th century market for figurative paintings in Italy. Few studies look explicitly at US artists. Galenson and Weinberg (2000) show how American artists born 1870 to 1940 introduced innovation into their art and how it influenced their careers. Alper and Wassal (1998) explore the determinants of persistence in artistic occupations, using the 1970 US Census. Alper and Wassal (2006) study employment and earnings of American artists using decennial US Census data from 1940 to 2000. Relative to this strand, I am able to explore data for a period of an unprecedented length 
covering 170 years and to shed light on the socio-economic background of average artists as opposed to the famous achiever.

The second related strand focuses on the geographic concentration of artistic activity. Artists exhibit remarkable clustering patterns, both in terms of birth and migration. The predominant location for visual artists born in the first half of the 20th century is New York City, with all prominent American artists clustering there (O'Hagan and Hellmanzik, 2008). New York is also a major work location for music composers: It is the fifth most important city for composers born in the 19th century and, after Paris, the second most popular destination for 20th century composers (O'Hagan and Borowiecki, 2010; Borowiecki and O'Hagan, 2012). Globally, Paris was the predominant music center over a remarkably long period of around four centuries and this was due to its large size (Borowiecki, 2015a). However, the incidence of the second World War caused a significant negative shock that led to massive relocations from the French capital to New York City.

An imminent benefit of geographic clustering is related to the existence of strong productivity gains. It has been shown that literary artists born between 1750 and 1925 experienced significant productivity gains when working in London, the predominant cluster within literary arts (Mitchell, 2019). Visual artists born 1850 to 1945 peaked earlier in the geographic clusters of Paris and New York (Hellmanzik, 2010). Music composers born in the late 18th and 19th centuries were more productive in the main hubs for music (Borowiecki, 2013) and the benefits increased with the peer group size at a decreasing rate (Borowiecki, 2015a). The focus in these studies is, however, on selected, specific artistic domains, and while interdisciplinary spill-overs are sometimes acknowledged (e.g., Borowiecki, 2013, describes how composers in Paris have been in contact with literary and visual artists), little is known about how these domains interrelate or interlocate.

Third, this research relates to the literature on the attractiveness of cities. Most 
closely related is the research on how cultural amenities can attract high-skilled workers (e.g., Falck et al., 2015), which then in turn leads to various positive spillovers. Clustering of creative activity in cities may also have broader, long-term effects on economic development. For example, by exploring the role of density in knowledge spillovers, Knudsen et al. (2008) show how geographic proximity may enhance innovation in US regions, while Maloney and Caicedo (2014) disclose how the historical concentration of innovative capacity, captured by the density of engineers, can explain income differences between Latin America and North America. The underlying research does not explicitly address the question of the consequences of cultural activity. Nonetheless, by outlining the dynamics and geography of emerging or established creative clusters, it provides important insights into the attractiveness of cities.

\section{Data}

There are two main databases used here. First, I use US census data from the Integrated Public Use Microdata Series database IPUMS (2015). This comprehensive decennial population census was first undertaken in 1790, but only provides information from 1850 on occupational status (OCC1950), along with a wide array of background variables. The occupation variable is used in order to identify the following creatives: Artists and art teachers, authors, musicians and music teachers, and actors and actresses. ${ }^{3}$ The occupation categories of artists and musicians also include the teachers within these domains. This is not necessarily a shortcoming, since also the presence of art teachers (be it in music or visual arts) serves as a

\footnotetext{
${ }^{3}$ The records also make it possible to identify architects, dancers and dancing teachers, and editors and reporters. However, these occupations are very rare and deliver an insufficiently low number of observations, especially in the earlier periods. In analogy to creative occupations, I will refer to non-creative occupations when writing about occupations other than those of artists, musicians, authors, and actors. This is done merely for convenience, as opposed to the categorization of occupations into those that require or do not require creative talent.
} 
proxy for creative activity. In places with more art teachers, more artists are educated and a higher population of artists can be expected, which in consequence leads to greater artistic activity and creativity. The possible overrepresentation of teachers is nonetheless addressed econometrically in the results section, where I also control for the geographic spread of teachers.

The social setting or technical content of artistic occupations has likely changed over a period of one and a half centuries. Nonetheless, larger occupational groupings are claimed to constitute relatively accurate and consistent indicators of social status and general function (IPUMS, 2017). Hence, in our case at the very least the overall group of creative occupations should be useful in reflecting the trends studied. Furthermore, it is argued that the "specific occupational titles are less subject to meaningful change than common historical wisdom would suggest" (IPUMS, 2017). In any case, the harmonized occupation series used should work well as a means of locating individuals in the occupational structure as well as in geographic space and this as far back as the late nineteenth century.

The IPUMS provides 1\%-samples for each of the available decades ("1-in-100 national random sample"), which are commonly used and also chosen for the underlying study. Furthermore, the focus of the analysis is on household heads. Focusing on household heads is important as they were typically the decision makers, and hence also took the decisions about location choice. This is crucial for an unbiased geographic analysis. Furthermore, narrowing down the analysis to household heads, who are typically the main breadwinners, filters out meaningful artistic occupations.

Given the particularly long time period covered here it is natural that some of Census questions or universe have changed. It is important to note that these decisions about the design of each Census have been made quite certainly independently from developments in the labor market of creatives. Furthermore, the changes go in 
either direction (e.g., slight increases or decreases in the cut-off age). Of course, the census changes may still lead to biased estimates, however - given the long timeperiod covered - they should not be very meaningful on average. Any subjective judgments and data interference have been avoided in the underlying paper as far as only possible and reasonable, however during pilot studies various data restrictions and censoring have been conducted, and no meaningful differences have arised.

Appendix Figure 9 visualizes the fast growth in the share of creatives across the domains covered. Over the second half of the 19th century the share of creative increases to about one in 1'000 respondents. The share of musicians is especially high and takes off during late 20th century until it reaches more than 0.5 percent. The remaining creative occupations fluctuate in a range between 0.1 and 0.15 percent. The higher uptake of these occupations by the population reflects the gradual increase in the popularity of creative occupations.Furthermore, from a technical point of view, it can be observed that the number of observations is sufficient for a quantitative analysis even for the earliest census editions. However, one has to bear in mind a potentially higher volatility over those years.

The second database used is the comprehensive biographical compendium - the Index Bio-bibliographicus Notorum Hominum (IBN). IBN is aimed to facilitate the global research community easy access to existing biographical sources. The information in the IBN was compiled from around 3'000 biographical sources (mainly dictionaries and encyclopedias) covering almost all countries and historical periods. ${ }^{4}$ The compendium lists 56'657 creatives (out of approx. 298'000 famous people) and provides for each person the name, birth and death places and a brief description of the individual's background. This allows me to filter out a set of 2'421 prominent creatives who were born or died in the US, which includes visual artists (1'060), authors (782), musicians (470), and actors (300). Appendix Figure 10 shows the number of deaths

\footnotetext{
${ }^{4}$ The IBN data used in the underlying study has been generously provided by David de la Croix and its meticulous collection has been described in Croix and Licandro (2015).
} 
of famous IBN creatives that occurred during the decade preceding a given census edition.

\section{Results}

\subsection{The socio-economic background of creatives since 1850}

This section presents the socio-economic background of the creatives covered by applying a simple regression model. In particular, a Probit model is estimated to explore how the probability to be involved in any of the four creative occupations covered (creative) is related to the background of an individual. These estimations are complemented in the Appendix B with graphical analyses outlining how the background of creatives change over time and differ across domains.

The explanatory variables include a dummy for gender (Female, which takes the value one if the respondent is female, and zero otherwise), a quadratic age polynomial (Age and Age2), a set of indicator variables that identify the marital status (Married, Separated, Divorced and Widowed; Single is the baseline category), the number of own family members in household (Family size), the number of own children in the household (Number of children) and a set of dummy variables that identify the race (Black, Native, Asian, Other, Mixed; White is the baseline category). The Probit model marginal effects are reported in Table 1. Most coefficients turn out to be statistically significant, but since this is co-driven by the high number of observations, the following interpretation will focus on the direction of the effects.

Females are more likely to engage in a creative occupation than males. Being a woman increases the probability of having a creative occupation by 0.0018 , holding all else equal. Given the average proportion of people having one of the creative 
occupations, the probability increase for female is quite sizeable and implies an increase by about 33 percent. Controlling for all other variables, the probability of an individual having a creative occupation increases with age, but at a decreasing rate. This can be interpreted as follows: a one unit change in the age variable, increases the probability of having a creative occupation by about 0.000324 . Given the average proportion of creatives this implies a rise in the probability of having a creative occupation by almost six percent. As we have seen previously, the results show also that those who are married, separated, divorced or widowed are less likely to take up a creative occupation than singles. Family size negatively affects the likelihood of having an artistic occupation, while the number of children - another measure of personal commitment - is insignificantly related. On average, the black and Asian groups are less likely to engage in creative work than whites.

\section{Insert Table 1 here}

The model is then extended by education and income variables. Educational attainment, which is available from 1940, is measured on an ordinal scale between zero and 11, as described previously. Income is measured in two ways. First, the model includes labor only income (earnings), which is measured as the total pre-tax wage and salary income for the previous year and is available from 1940. This variable captures the effects of an artists' remuneration and hence is directly related to the financial incentives of choosing a creative occupation. Second, the model takes account of total family income, which is measured as the total pre-tax money income earned by one's family from all sources for the previous year, including non-labor income. This variable is available from 1950 and its inclusion is motivated by the fact that the participation decision depends likely not only on one's own earnings, but on the total income of the family. Both income variables have been adjusted for inflation.

Column (2) of Table 1 summarizes the results. It can be observed that better ed- 
ucation increases the probability of a person having a creative occupation. On the other hand, earnings are negatively related with creative occupations - an association that is often found for creative workers, who typically earn less than the average (e.g., Alper and Wassal, 2006). Or from another perspective: The low earnings of artists are detrimental to taking up of an artistic occupations. Interestingly, total family income exhibits a positive relation with the uptake of a creative occupation. This is in line with the notion that potential access to family's financial support is a factor conducive in the participation decision. Having access to financial resources facilitates the uptake of a creative occupation and the associated lower earnings and potentially higher uncertainties.

The baseline model is further extended by the inclusion of controls for migrants and logged city population. In column (3) it can be observed that these additional controls decrease the number of observations to about 1.3 million (from the previously almost 4 million observations). The newly added variables indicate that migrants are more likely to have a creative occupation, as are those who locate in larger agglomerations. The remaining, previously presented results remain robust.

\section{Insert Table 2 here}

Next, Table 2 provides the baseline results disaggregated by the creative domain. Males are less likely to be authors or musicians, but somewhat more likely to work as actors. The other meaningful difference is that the probability of being an actor decreases with age. This supports the notion that actors, especially in the movie industry, are predominantly male and typically young. The online appendix presents further results disaggregated by creative domain for a model with education and income controls (Table 5) and with migrant and city size controls (Table 6). 


\subsection{The historical development of artistic clusters}

This section provides historical insights into the geographic clustering patterns of creative activity in the United States. In the following depictions, the total number of creatives, as opposed to the share per population, is shown, and there are three reasons for this. First, it is established that the total number of artists (not the density) matters for benefits associated with peer effects: Whether artists are based in a small or large city, the experienced benefits are related to the size of the artist population (Borowiecki, 2015a). Second, it is more likely that the total number matters more for the attraction of high-skilled workers and possibly for spillover effects of creativity from the arts to the economic sectors. This is also supported by the observation that larger cities typically have cultural infrastructures that allow artists to reach greater audiences (e.g., a larger concert hall). Third, artists usually cluster in certain districts of a city, and hence considering the population size of a whole city as a denumerator would be misleading, and an intra-city approach is not feasible in this research. ${ }^{5}$

Initially, we analyze the geography of artistic talent by looking at the birthplaces and deathplaces of famous IBN creatives. Even though artists are highly mobile, there exists a very high correlation between their workplace and birthplace or deathplace. Furthermore, it is fairly established that the births of famous creatives typically occur in places where a given artistic domain has already been developed (for evidence and discussion see, for example, O’Hagan and Borowiecki, 2010; Borowiecki and O'Hagan, 2012).

The maps depicting the birthplaces or deathplaces of IBN creatives are presented in Figures 2 and 3, respectively. Each map indicates by a scaled point the importance of a city as a birthplace for a certain group of creatives and by shades the impor-

\footnotetext{
${ }^{5}$ The density maps are nonetheless presented in Appendix D.2, while population differences are accounted for econometrically in models estimated later in this section.
} 
tance of a state. ${ }^{6}$ Creative activity is primarily located in the Mid Atlantic, North Eastern, and Mid Western regions, and along the West Coast. The geographic concentration is more intense for the deathplaces - this supports the previously posited high migration intensity (both internal migration and immigration). Across all creative domains studied, New York City emerges as the consistently largest cluster city, followed by Boston, Chicago, Los Angeles, and San Francisco. ${ }^{7}$

Insert Figure 2 here

Insert Figure 3 here

There are, however, also clear differences across the domains. For example, New Orleans is found to be a place with a very high concentration of births of musicians. In New Orleans funk was supposedly played for the first time ever but more importantly, it is the city where jazz originated. The insight that a significant number of famous musicians were born here lends support to the colloquial label assigned to the city as the birthplace of jazz. Another example is St. Louis, a city strongly associated with blues, but also jazz and ragtime. Interestingly though, while these two cities emerge as unusually important birthplaces, markedly fewer deaths are observed there. This indicates that many of the famous individuals born here migrated away. Perhaps the most famous example is Louis Armstrong, who was born in New Orleans, but died in New York City, where he also spent a significant part of his career.

The concentration intensity of the census creatives (the "average" creatives) is shown in Figure 4. The geographic spread of the census creatives is considerably greater, while the clustering intensity appears to be somewhat lower - albeit still very noticeable - in comparison with the famous creatives. The greater spread is partly caused

\footnotetext{
${ }^{6}$ For some few observations the exact city was not available, and only information on the county or state was provided.

${ }^{7}$ Miami also receives some prominence when it comes to deaths, but this is possibly more related to the fact that it is a popular destination for retirement.
} 
by the higher number of observations available for the census sample. However, the findings also indicate that extraordinary talent concentrates more than average individuals. Furthermore, it is interesting to observe that several dominant clusters emerge, and these are very similar as in the case of famous creatives.

\section{Insert Figure 4 here}

Next, analyses of the changes in locations over time are presented. The famous IBN creatives are observed for a period from before the census; hence, the earliest period covers the years before 1850. Figure 5 depicts for this period the deaths of artists in the top-left panel, followed by three additional time intervals: 18501890, 1900-1940, and 1950-1980. The earliest period covers locations restricted to the East Coast: New York City, Boston, Philadelphia, and Charleston. Over time, the spread extends to the Mid West and later also to the West Coast, in particular California. A comparable development is observed if one looks at the location of census respondents in Figure 6, now beginning with the period 1850 to 1890, and extending in the last period to the years from 1980 to 2010. Qualitatively the story of geographic spread is comparable with the IBN creatives; however, as previously noted, the clustering intensity is less marked. These maps more closely reflect the geographic concentration of the population across the United States; however, the clustering patterns go beyond demographic factors. Some of the cities have a clearly overrepresented share of artists (e.g., Chicago), whereas other large cities are characterized by a relatively insignificant population of artists (e.g., Houston).

The presented trends resonate with the wider economic context in several regards. The early economic development in the New England region has been stimulated by a range of subsidies to, for example, improve the infrastructure or by the introduction of early improved institutions, such as a legal system conducive to business activity (Newell, 2000). The decreasing cost of transportation, related to the introduction of railroads but not only, connected the North and Midwest, which in turn stimulated 
not only migration, but also economic growth (Fogel, 1965). The rapid expansion of settlements to the West opened up vast frontier lands, which became connected by rail already in 1869, and with the advent of the automobile decreased further the travel cost. Improved connectivity and the resulting high inflow of workers contributed to the spread of people, goods, and also ideas.

\section{Insert Figure 5 here}

Figure 7 depicts the clustering patterns of actors, which are particularly fascinating. The deaths of all famous IBN actors before 1840 occurred in New York City, later also in other cities of the Mid West, and eventually on the West Coast, quite as for artists. However, the period after 1950 shows a remarkable concentration in just two cities: New York and Los Angeles. Very similar results emerge if one looks at the more numerous observations from the census data in Figure 8: The two cities are the only cluster locations and it is remarkable how they dominate the landscape. The dominance of Los Angeles is related to the rapid growth of Hollywood and is in line with other economic history accounts of the development and dominance of the US movie industry (e.g., Bakker, 2005; Sedgwick and Pokorny, 2010). ${ }^{8}$

\section{Insert Figure 7 here \\ Insert Figure 8 here}

Next, I turn to a quantitative exploration of cluster interdependencies and explore how cluster sizes of various domains relate to each other. Table 3 illustrates these relationships for census creatives (columns 1 to 3 ) and famous IBN creatives (columns 4 to 6 ). The models now include city and year fixed effects to account for unobservable differences across cities and time. To account for differences in city size, all models include further controls for the logged population of a city. Since two of the creative occupations include teachers (i.e., artists and musicians), I further include

\footnotetext{
${ }^{8}$ Changes over time in clustering patterns for IBN and census musicians are depicted in Appendix Figures 17 and 18, and for authors in Figures 19 and 20.
} 
controls for the number of teachers, as recorded by the census.

Insert Table 3 here

The correlations are positive and typically estimated with high statistical precision. For example, in column (1) we can observe that a one percent increase in the number of authors or musicians is associated with a $0.14 \%$ or $0.1 \%$ increase in the population of artists, respectively. However, the association is typically insignificant for census actors. This may be related to the fact that actors tend to cluster in predominantly two cities only, one of which is Los Angeles, which is typically regarded as a mature and highly competitive center of the film industry. ${ }^{9}$ More creatives are found in larger cities: The point estimate of the city size implies that an increase in city size by $1 \%$ is associated with $0.8 \%$ more artists. We also observe that the control for teachers is estimated positively (even if statistically insignificant) for artists and musicians - the two categories that include teachers as well.

For the case of famous creatives it can be seen in columns (4)-(6) that all correlation coefficients are highly significant and also considerably greater in size. Here a one percent higher number of any type of creative is typically associated with a $0.15-0.75$ percent higher number of other creatives. All in all, these insights constitute two important findings. First, creatives mix: cities that are the domicile for a certain type of creatives (e.g., visual artists) are typically also more popular among individuals from other creative domains (e.g., authors or musicians). Second, the best cluster more intensely: in cities where a famous creative is based (e.g., a famous visual artist), the probability to have in the same city a famous creative from another creative field (e.g., a famous musician) is higher than in the case of average creatives.

\footnotetext{
${ }^{9}$ Anecdotally, film directors in Los Angeles are sometimes seen as followers of a business plan, producing entertainment, whereas filmmaking in New York City can be less tense and perhaps more artistic.
} 


\subsection{The role of famous artists}

Finally, I investigate the interplay between famous and average creatives. Here I explore the probability of a census respondent reporting a creative occupation and how this relates to the presence of famous creatives in the same city in the past. The estimated model is basically the same as reported previously in Table 2, but now in addition accounts for the history of significant artistic activity, measured as the number of deaths of famous IBN creatives that occurred in the decade prior to the given census. The identification of deaths measured at residence of census respondent during ten years prior to the given census enables a certain time lag for the person inspired by a famous IBN creative to become a creative herself.

\section{Insert Table 4 here}

The results are summarized in Table 4 and imply that places with greater artistic activity (i.e., where more creatives within a domain have died) are more likely to see more people involved in creative occupations within the same domain. This model is not suitable for making any strong causal claims; however, it seems likely that the presence of famous creatives has at least some impact on the future development of creative clusters.

\section{Conclusions}

Today, the role of creativity and the presence of creative people are arguably of immense importance for economic growth and the welfare of societies. And yet, research on these topics is typically limited to contemporary approaches and is usually conducted outside the field of economics. This study adds new insights into the historical development of creative activity and clusters of creativity. This is achieved by looking at the case of the arts, where the earliest creative achievements can be 
observed in a consistent and comparable way.

The underlying research documents the background of those involved in a creative occupation and furthermore illuminates how it has changed over the course of 170 years. Some of the disclosed patterns echo the overall socio-demographic trends of the period covered, but there are several novel and interesting insights: The proportion of female creatives is relatively high, time constraints can be a hindrance for taking up a creative occupation, racial inequality is present and tends to change only slowly, and access to financial resources within a family facilitates the uptake of an artistic occupation.

Furthermore, I shed light on the geography of creative clusters in the United States and explain how these have evolved over time and across various domains. Even though it may seem that some of the patterns are already known — for example, that New York City is a very significant center for the arts - the extent of the dominance has not yet been quantified before, nor has it been compared across creative domains. Finally, by linking the census records with data on famous IBN creatives, the role of famous individuals for the growth of local clusters and creative employment is explored. Famous creatives have a particular influence on people taking up creative occupations and are related to the size of creative centers. Typically, superstar economies (Rosen, 1981) are criticized by the public mainly due to the extreme earnings received by a small group of individuals at the very top of the income scale. The insights presented here point to a non-negligible positive externality of superstars in the form of a potentially long-lasting heritage that famous creatives leave behind.

This research gives rise to several new questions. In particular, the question of how the presence of a famous creative impacts others: Does she introduce new knowledge, practices, networks, or infrastructure, or a multiple of these factors, which then potentially persist over time? Or is it perhaps the case that her presence stimulates 
the demand within a creative domain due to factors related to local identity and heritage (for a related discussion, see Borowiecki, 2015b)?

Of interest for contemporary policy makers and the public is also whether and how the historical development of creative activity is nowadays related to creativity. Anecdotally, there seems to be a very high overlap between the creative clusters historically and the startup landscape in the United States these days. I have motivated this research by disclosing a strong and long-term correlation between artistic activity and entrepreneurial outcomes. According to Compass (2015), six US cities are listed among the global top-10 startup ecosystems, and the list begins with San Francisco (Silicon Valley), New York City, Los Angeles and Boston; that is, cities that have been identified in the underlying research as significant creative clusters in history. These cities are obviously also centers of higher education with some of the top universities in the country. Certainly the role of education cannot be overlooked, as it is likely at least as important as artistic activity in explaining why these areas are and have been centers of entrepreneurial outcomes (for a more detailed discussion see Goldin and Katz, 2010). However, while it is beyond the scope of this study to contribute to the debate on how artistic creativity is related to startup activity, it becomes clear that these concepts are related and very persistent over time, perhaps even more so than previously thought. 


\section{References}

Alper, Neil O. and Gregory H. Wassal, "Artists' Labor Market Experiences: A Preliminary Analysis Using Longitudinal Data," in M. Heikkinen and T. Koshinen, eds., Economics of Artists and Arts Policy: A Selection of Papers, Helsinki: The Arts Council of Finland, 1998.

_ and _, "Artists' Careers and Their Labor Markets," in V. Ginsburgh and D. Throsby, eds., Handbook of the Economics of Art and Culture, Amsterdam: Elsevier, 2006.

Ateca-Amestoy, Victoria, "Determining heterogeneous behavior for theater attendance," Journal of Cultural Economics, 2008, 32 (2), 127-151.

Bakker, Gerben, "The decline and fall of the European film industry: sunk costs, market size, and market structure, 1890-1927," Economic History Review, 2005, $58(2), 310-351$.

Benhamou, Francoise, "Artist's labour markets," in Ruth Towse, ed., A Handbook of Cultural Economics, Cheltenham: Edward Elgar Publishing, 2011, chapter 7, pp. $53-58$.

Borowiecki, Karol Jan, "Geographic clustering and productivity: An instrumental variable approach for classical composers," Journal of Urban Economics, 2013, 73 (1), 94-110.

_, "Agglomeration Economies in Classical Music," Papers in Regional Science, forthcoming, 2015a.

_ , "Historical origins of cultural supply in Italy," Oxford Economic Papers, 2015b, $67(3), 781-805$.

_, "How Are You, My Dearest Mozart? Well-being and Creativity of Three Famous Composers Based on their Letters," Review of Economics and Statistics, 
forthcoming, 2017.

_ and John W. O'Hagan, "Historical Patterns Based on Automatically Extracted Data: The Case of Classical Composers," Historical Social Research (Section 'Cliometrics'), 2012, 37 (2), 298-314.

Burger-Helmchen, Thierry, The Economics of Creativity: Ideas, Firms and Markets, London: Routledge, 2013.

Compass, "The Global Startup Ecosystem Ranking 2015," The Startup Ecosystem Report Series, 2015.

Crafts, Nicholas, British Economic Growth during the Industrial Revolution, Oxford: Clarendon Press, 1985.

de la Croix, David and Omar Licandro, "The longevity of famous people from Hammurabi to Einstein," Journal of Economic Growth, 2015, 20 (3), 263-303.

Etro, Federico and Laura Pagani, "The Market for Paintings in Italy During the Seventeenth Century," Journal of Economic History, 2012, 72, 423-447.

Fairlie, Robert W., Arnobio Morelix, E.J. Reedy, and Joshua Russell, The Kauffman Index 2015: Startup Activity. National Trends, Kansas City: Kauffman Foundation, 2015.

Falck, Oliver, Michael Fritsch, Stephan Heblich, and Anne Otto, "Music in the Air: Estimating the Social Return to Cultural Amenities," CESifo Working Paper Series No. 5183, 2015.

Florida, Richard, The rise of the creative class: And how it's transforming work, leisure, community, and everyday life, New York: Basic Books, 2002.

Fogel, Robert William, Railroads and American Economic Growth: Essays in Economic History, Baltimore: Johns Hopkin Press, 1965. 
Galenson, David W., Old Masters and Young Geniuses: The Two Life Cycles of Artistic Creativity, Princeton: Princeton University Press, 2007.

_ , "Creativity, Copyright and the Creative Industries Paradigm," NBER Working Paper Series 16024, 2010.

_ and Bruce A. Weinberg, "Age and the Quality of Work: The Case of Modern American Painters," Journal of Political Economy, August 2000, 108 (4), 761-777.

_ and _ , "Creating Modern Art: The Changing Careers of Painters in France from Impressionism to Cubism," American Economic Review, 2001, 91 (4), 1063-1071.

Gergaud, Olivier, Morgane Laouenan, and Etienne Wasmer, "A Brief History of Human Time: Exploring a database of 'notable people'," Sciences Po Economics Discussion Papers No 2016-03, 2016.

Goldin, Claudia, "The Quiet Revolution That Transformed Women's Employment, Education, and Family," American Economic Review, 2006, 96 (2), 1-21.

- and Lawrence F. Katz, The Race between Education and Technology, Boston: Harvard University Press, 2010.

Graddy, Kathryn, "Taste Endures! The Rankings of Roger de Piles and Three Centures of Art Prices," Journal of Economic History, 2013, 73, 765-790.

Grove Music Online, Oxford Music Online, Oxford University Press, 2013.

Heilbrun, James and Charles M. Gray, The Economics of Art and Culture, Cambridge University Press, 2001.

Hellmanzik, Christiane, "Location matters: Estimating cluster premiums for prominent modern artists," European Economic Review, February 2010, 54 (2), $199-218$.

IPUMS, "Integrated Public Use Microdata Series," https://usa.ipums.org/ 2015. Accessed: Spring 2015. 
_, "Integrated Occupation and Industry Codes and Occupational Standing Variables in the IPUMS," https://usa.ipums.org/usa/chapter4/chapter4.shtml 2017. Accessed: 2017-04-18.

Knudsen, Brian, Richard Florida, Kevin Stolarick, and Gary Gates, "Density and Creativity in U.S. Regions," Annals of the Association of American Geographers, 2008, $98(2), 461-478$.

Ludwig, Arnold M., The Price of Greatness: Resolving the Creativity and Madness Controversy, New York: The Guilford Press, 1995.

Maloney, William F. and Felipe Valencia Caicedo, "Engineers, Innovative Capacity and Development in the Americas," IZA Discussion Paper No. 8271, 2014.

Menger, Pierre-Michel, The Economics of Creativity: Art and Achievement under Uncertainty, Boston: Harvard University Press, 2014.

Mitchell, Sara, "London Calling? Agglomeration Economies in Literature since 1700," Journal of Urban Economics, 2019, 112, 16-32.

Newell, Margaret Alan, "The Birth of New England in the Atlantic Economy: From its Beginning to 1770," in Peter Temin, ed., Engines of Enterprise: An Economic History of New England, Boston: Harvard University Press, 2000, p. 11-68.

OECD, Resilient Economies for Inclusive Societies, Paris: OECD, 2014.

O'Hagan, John W. and Christiane Hellmanzik, "Clustering and Migration of Important Visual Artist: Broad Historical Evidence," Historical Methods: A Journal of Quantitative and Interdisciplinary History, 2008, 40 (3), 121-36.

- and Karol Jan Borowiecki, "Birth Location, Migration and Clustering of Important Composers: Historical Patterns," Historical Methods: A Journal of Quantitative and Interdisciplinary History, 2010, 43 (2), 81-91. 
Rosen, Sherwin, "The Economics of Superstars," American Economic Review, 1981, 71 (5), 845-858.

Sedgwick, John and Michael Pokorny, "Profitability trends in Hollywood, 1929 to 1999: Somebody must know something," Economic History Review, 2010, 63 (1), 56-84.

Throsby, David, Economics and Culture, Cambridge: Cambridge University Press, 2001.

Towse, Ruth, "Creativity, Copyright and the Creative Industries Paradigm," Kyklos, 2010, 63 (3).

UNCTAD, Creative Economy: A Feasible Development Option, Geneva: UNCTAD, 2010.

Weber, Clint B., The Treasured Collection of Golden Heart Farm: A Biography of Wilhelmina Weber Furlong, New York: The Weber Furlong Publishing Company, 2012. 
6 Tables 


\begin{tabular}{|c|c|c|c|}
\hline VARIABLES & $\begin{array}{c}(1) \\
\text { Probit } \\
\text { creative }\end{array}$ & $\begin{array}{c}(2) \\
\text { Probit } \\
\text { creative } \\
\text { from } 1950 \text { only }\end{array}$ & $\begin{array}{c}(3) \\
\text { Probit } \\
\text { creative }\end{array}$ \\
\hline female & $\begin{array}{c}0.00183^{* * *} \\
(0.000104)\end{array}$ & $\begin{array}{c}0.00100 * * * \\
(9.20 \mathrm{e}-05)\end{array}$ & $\begin{array}{c}0.000202 \\
(0.000159)\end{array}$ \\
\hline age & $\begin{array}{c}0.000320^{* * *} \\
(1.41 \mathrm{e}-05)\end{array}$ & $\begin{array}{c}0.000266^{* * *} \\
(1.41 \mathrm{e}-05)\end{array}$ & $\begin{array}{c}0.000326^{* * *} \\
(2.43 \mathrm{e}-05)\end{array}$ \\
\hline $\operatorname{age}^{2}$ & $\begin{array}{c}-3.97 \mathrm{e}-06^{* * *} \\
(1.43 \mathrm{e}-07)\end{array}$ & $\begin{array}{c}-2.91 \mathrm{e}-06^{* * *} \\
(1.41 \mathrm{e}-07)\end{array}$ & $\begin{array}{c}-4.29 \mathrm{e}-06 * * * \\
(2.53 \mathrm{e}-07)\end{array}$ \\
\hline married & $\begin{array}{c}-0.00106^{* * *} \\
(0.000134)\end{array}$ & $\begin{array}{c}-0.000775^{* * *} \\
(0.000135)\end{array}$ & $\begin{array}{c}-0.00163^{* * *} \\
(0.000212)\end{array}$ \\
\hline separated & $\begin{array}{c}-0.00244^{* * *} \\
(0.000161)\end{array}$ & $\begin{array}{c}-0.00109 * * * \\
(0.000186)\end{array}$ & $\begin{array}{c}-0.00241^{* * *} \\
(0.000267)\end{array}$ \\
\hline divorced & $\begin{array}{c}-0.00139 * * * \\
(0.000113)\end{array}$ & $\begin{array}{c}-0.000612^{* * *} \\
(0.000115)\end{array}$ & $\begin{array}{c}-0.000740^{* * *} * \\
(0.000204)\end{array}$ \\
\hline widowed & $\begin{array}{c}-0.00367^{* * *} \\
(0.000108)\end{array}$ & $\begin{array}{c}-0.00212^{* * *} \\
(0.000132)\end{array}$ & $\begin{array}{c}-0.00338 * * * \\
(0.000185)\end{array}$ \\
\hline family size & $\begin{array}{c}-0.00108^{* * *} \\
(7.37 \mathrm{e}-05)\end{array}$ & $\begin{array}{c}-0.000762^{* * *} \\
(8.70 \mathrm{e}-05)\end{array}$ & $\begin{array}{c}-0.000971^{* * *} \\
(0.000101)\end{array}$ \\
\hline number children & $\begin{array}{l}-0.000123 \\
(8.40 \mathrm{e}-05)\end{array}$ & $\begin{array}{c}8.13 \mathrm{e}-05 \\
(9.75 \mathrm{e}-05)\end{array}$ & $\begin{array}{c}-0.000515^{* * *} \\
(0.000120)\end{array}$ \\
\hline black & $\begin{array}{c}-0.00267^{* * *} \\
(9.58 \mathrm{e}-05)\end{array}$ & $\begin{array}{c}-0.00144^{* * *} \\
(0.000107)\end{array}$ & $\begin{array}{c}-0.00371^{* * *} \\
(0.000129)\end{array}$ \\
\hline native & $\begin{array}{l}-0.000801 \\
(0.000501)\end{array}$ & $\begin{array}{c}0.000650 \\
(0.000571)\end{array}$ & $\begin{array}{l}-0.00138^{*} \\
(0.000819)\end{array}$ \\
\hline asian & $\begin{array}{c}-0.00227^{* * *} \\
(0.000156)\end{array}$ & $\begin{array}{c}-0.00253^{* * *} \\
(0.000119)\end{array}$ & $\begin{array}{c}-0.00331^{* * *} \\
(0.000185)\end{array}$ \\
\hline other & $\begin{array}{c}-0.00370 * * * \\
(0.000140)\end{array}$ & $\begin{array}{c}-0.00148 * * * \\
(0.000216)\end{array}$ & $\begin{array}{c}-0.00451^{* * *} \\
(0.000151)\end{array}$ \\
\hline mixed & $\begin{array}{l}-0.000508 \\
(0.000339)\end{array}$ & $\begin{array}{c}0.000225 \\
(0.000341)\end{array}$ & $\begin{array}{c}-0.00131^{* * *} \\
(0.000484)\end{array}$ \\
\hline earnings & & $\begin{array}{c}-5.59 \mathrm{e}-05^{* * *} \\
(1.16 \mathrm{e}-06)\end{array}$ & \\
\hline family income & & $\begin{array}{c}1.03 \mathrm{e}-05^{* * *} \\
(5.71 \mathrm{e}-07)\end{array}$ & \\
\hline education & & $\begin{array}{c}0.00172^{* * *} \\
(1.60 \mathrm{e}-05)\end{array}$ & \\
\hline migrant & & & $\begin{array}{c}0.00171^{* * *} \\
(0.000126)\end{array}$ \\
\hline $\log ($ city population $)$ & & & $\begin{array}{c}0.00102^{* * *} \\
(5.65 \mathrm{e}-05)\end{array}$ \\
\hline Observations & $3,924,696$ & $3,068,687$ & $1,330,482$ \\
\hline State FE & $\checkmark$ & $\checkmark$ & $\checkmark$ \\
\hline Year FE & $\checkmark$ & $\checkmark$ & $\checkmark$ \\
\hline
\end{tabular}

Robust standard errors in parentheses *** $\mathrm{p}<0.01, * * \mathrm{p}<0.05,{ }^{2} \hat{\mathrm{p}}<0.1$

Table 1: Socio-economic background of creatives 


\begin{tabular}{|c|c|c|c|c|}
\hline VARIABLES & $\begin{array}{c}(1) \\
\text { Probit } \\
\text { artist }\end{array}$ & $\begin{array}{c}(2) \\
\text { Probit } \\
\text { author }\end{array}$ & $\begin{array}{c}(3) \\
\text { Probit } \\
\text { musician }\end{array}$ & $\begin{array}{c}(4) \\
\text { Probit } \\
\text { actor }\end{array}$ \\
\hline female & $\begin{array}{c}2.26 \mathrm{e}-05 \\
(4.18 \mathrm{e}-05)\end{array}$ & $\begin{array}{c}0.000117^{* * *} \\
(2.40 \mathrm{e}-05)\end{array}$ & $\begin{array}{c}0.00166^{* * *} \\
(8.58 \mathrm{e}-05)\end{array}$ & $\begin{array}{c}-2.84 \mathrm{e}-05^{* *} \\
(1.28 \mathrm{e}-05)\end{array}$ \\
\hline age & $\begin{array}{c}8.47 \mathrm{e}-05^{* * *} \\
(6.32 \mathrm{e}-06)\end{array}$ & $\begin{array}{c}4.22 \mathrm{e}-05^{* * *} \\
(3.49 \mathrm{e}-06)\end{array}$ & $\begin{array}{c}0.000175^{* * *} \\
(1.11 \mathrm{e}-05)\end{array}$ & $\begin{array}{c}1.25 \mathrm{e}-06 \\
(1.86 \mathrm{e}-06)\end{array}$ \\
\hline $\operatorname{age}^{2}$ & $\begin{array}{c}-1.04 \mathrm{e}-06^{* * *} \\
(6.66 \mathrm{e}-08)\end{array}$ & $\begin{array}{c}-4.50 \mathrm{e}-07 * * * \\
(3.55 \mathrm{e}-08)\end{array}$ & $\begin{array}{c}-2.24 \mathrm{e}-06^{* * *} \\
(1.12 \mathrm{e}-07)\end{array}$ & $\begin{array}{c}-4.36 \mathrm{e}-08^{* *} \\
(1.92 \mathrm{e}-08)\end{array}$ \\
\hline married & $\begin{array}{c}-0.000326^{* * *} \\
(5.80 \mathrm{e}-05)\end{array}$ & $\begin{array}{l}-5.39 \mathrm{e}-05 \\
(3.33 \mathrm{e}-05)\end{array}$ & $\begin{array}{c}-0.000440 * * * \\
(0.000105)\end{array}$ & $\begin{array}{c}-9.69 \mathrm{e}-05^{* * *} \\
(2.15 \mathrm{e}-05)\end{array}$ \\
\hline separated & $\begin{array}{c}-0.000502^{* * *} \\
(6.55 \mathrm{e}-05)\end{array}$ & $\begin{array}{c}-0.000242^{* * *} \\
(3.27 \mathrm{e}-05)\end{array}$ & $\begin{array}{c}-0.00139^{* * *} \\
(0.000135)\end{array}$ & $\begin{array}{c}-8.72 \mathrm{e}-05^{* * *} \\
(2.15 \mathrm{e}-05)\end{array}$ \\
\hline divorced & $\begin{array}{c}-0.000286 * * * \\
(4.64 \mathrm{e}-05)\end{array}$ & $\begin{array}{c}-0.000222^{* * *} \\
(2.08 \mathrm{e}-05)\end{array}$ & $\begin{array}{c}-0.000692^{* * *} \\
(9.42 \mathrm{e}-05)\end{array}$ & $\begin{array}{l}-8.09 \mathrm{e}-06 \\
(1.85 \mathrm{e}-05)\end{array}$ \\
\hline widowed & $\begin{array}{c}-0.000784^{* * *} \\
(4.23 \mathrm{e}-05)\end{array}$ & $\begin{array}{c}-0.000396^{* * *} \\
(2.15 \mathrm{e}-05)\end{array}$ & $\begin{array}{c}-0.00209^{* * *} \\
(9.31 \mathrm{e}-05)\end{array}$ & $\begin{array}{c}-9.16 \mathrm{e}-05^{* * *} \\
(1.56 \mathrm{e}-05)\end{array}$ \\
\hline family size & $\begin{array}{c}-0.000230 * * * \\
(3.15 \mathrm{e}-05)\end{array}$ & $\begin{array}{c}-0.000218^{* * *} \\
(2.27 \mathrm{e}-05)\end{array}$ & $\begin{array}{c}-0.000553^{* * *} \\
(5.68 \mathrm{e}-05)\end{array}$ & $\begin{array}{c}-3.80 \mathrm{e}-05^{* * *} \\
(1.06 \mathrm{e}-05)\end{array}$ \\
\hline number children & $\begin{array}{l}-3.43 \mathrm{e}-06 \\
(3.52 \mathrm{e}-05)\end{array}$ & $\begin{array}{c}0.000101^{* * *} \\
(2.58 \mathrm{e}-05)\end{array}$ & $\begin{array}{c}-0.000148^{* *} \\
(6.53 \mathrm{e}-05)\end{array}$ & $\begin{array}{c}-3.59 \mathrm{e}-05^{* * *} \\
(1.22 \mathrm{e}-05)\end{array}$ \\
\hline black & $\begin{array}{c}-0.001000^{* * *} \\
(3.03 \mathrm{e}-05)\end{array}$ & $\begin{array}{c}-0.000425^{* * *} \\
(1.80 \mathrm{e}-05)\end{array}$ & $\begin{array}{c}-0.000969^{* * *} \\
(8.58 \mathrm{e}-05)\end{array}$ & $\begin{array}{c}-6.02 \mathrm{e}-05^{* * *} \\
(1.57 \mathrm{e}-05)\end{array}$ \\
\hline native & $\begin{array}{c}0.000138 \\
(0.000241)\end{array}$ & $\begin{array}{c}-0.000246^{* * *} \\
(8.13 \mathrm{e}-05)\end{array}$ & $\begin{array}{l}-0.000424 \\
(0.000406)\end{array}$ & $\begin{array}{c}-8.50 \mathrm{e}-05^{*} \\
(5.15 \mathrm{e}-05)\end{array}$ \\
\hline Asian & $\begin{array}{c}-0.000175^{* *} \\
(7.93 \mathrm{e}-05)\end{array}$ & $\begin{array}{c}-0.000317^{* * *} \\
(2.43 \mathrm{e}-05)\end{array}$ & $\begin{array}{c}-0.00127^{* * *} \\
(0.000133)\end{array}$ & $\begin{array}{c}-0.000132^{* * *} \\
(1.20 \mathrm{e}-05)\end{array}$ \\
\hline other & $\begin{array}{c}-0.000645^{* * *} \\
(6.33 \mathrm{e}-05)\end{array}$ & $\begin{array}{c}-0.000429^{* * *} \\
(1.88 \mathrm{e}-05)\end{array}$ & $\begin{array}{c}-0.00210^{* * *} \\
(0.000125)\end{array}$ & $\begin{array}{c}-0.000111^{* * *} \\
(1.66 \mathrm{e}-05)\end{array}$ \\
\hline mixed & $\begin{array}{l}-0.000123 \\
(0.000152)\end{array}$ & $\begin{array}{c}-0.000142^{* *} \\
(5.91 \mathrm{e}-05)\end{array}$ & $\begin{array}{l}-0.000357 \\
(0.000271)\end{array}$ & $\begin{array}{c}0.000129 * * \\
(6.28 \mathrm{e}-05)\end{array}$ \\
\hline Observations & $3,920,693$ & $3,886,419$ & $3,924,696$ & $2,616,117$ \\
\hline State FE & $\checkmark$ & $\checkmark$ & $\checkmark$ & $\checkmark$ \\
\hline Year FE & $\checkmark$ & $\checkmark$ & $\checkmark$ & $\checkmark$ \\
\hline
\end{tabular}

Table 2: Socio-economic background of creatives by domain 


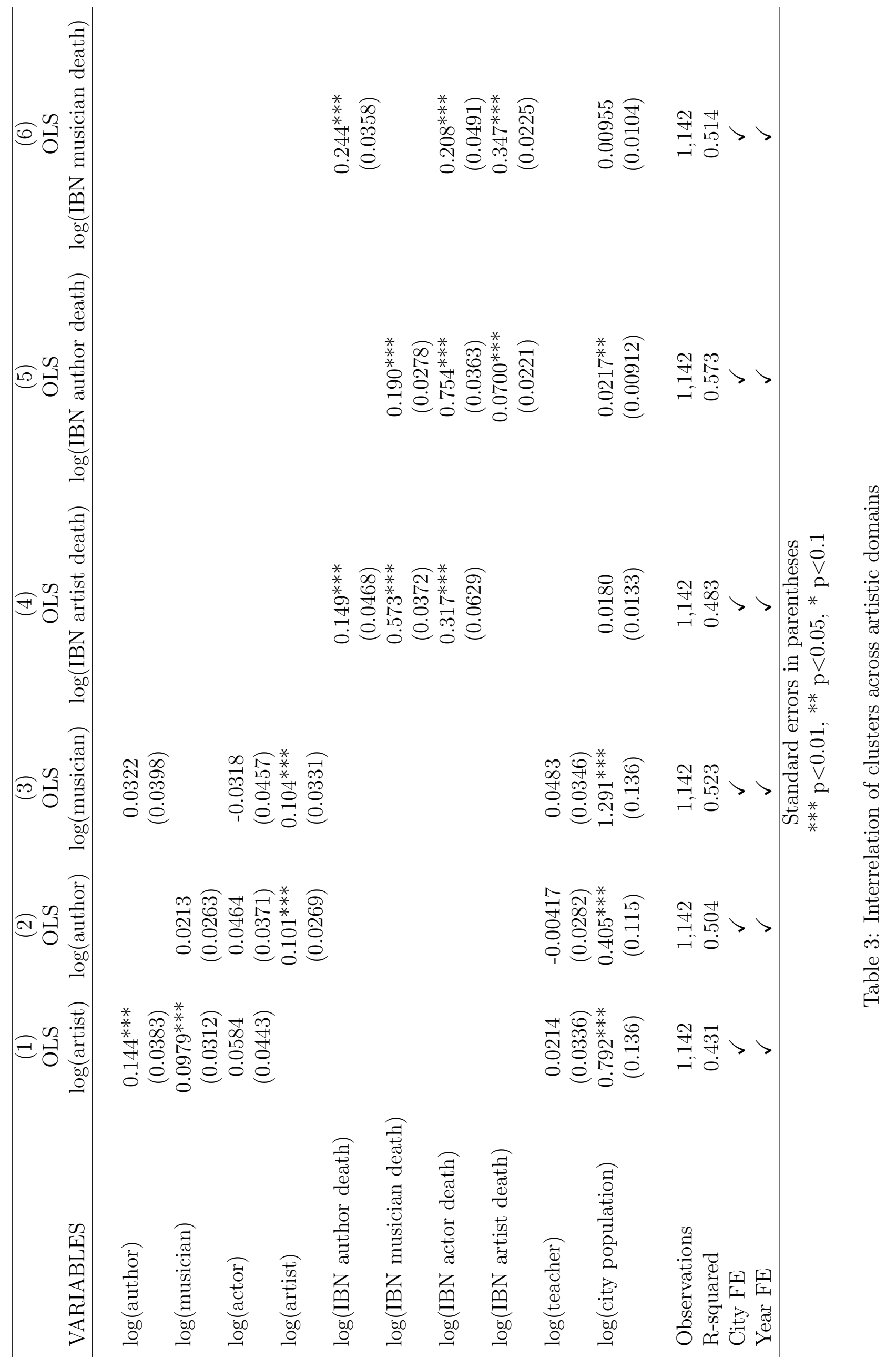




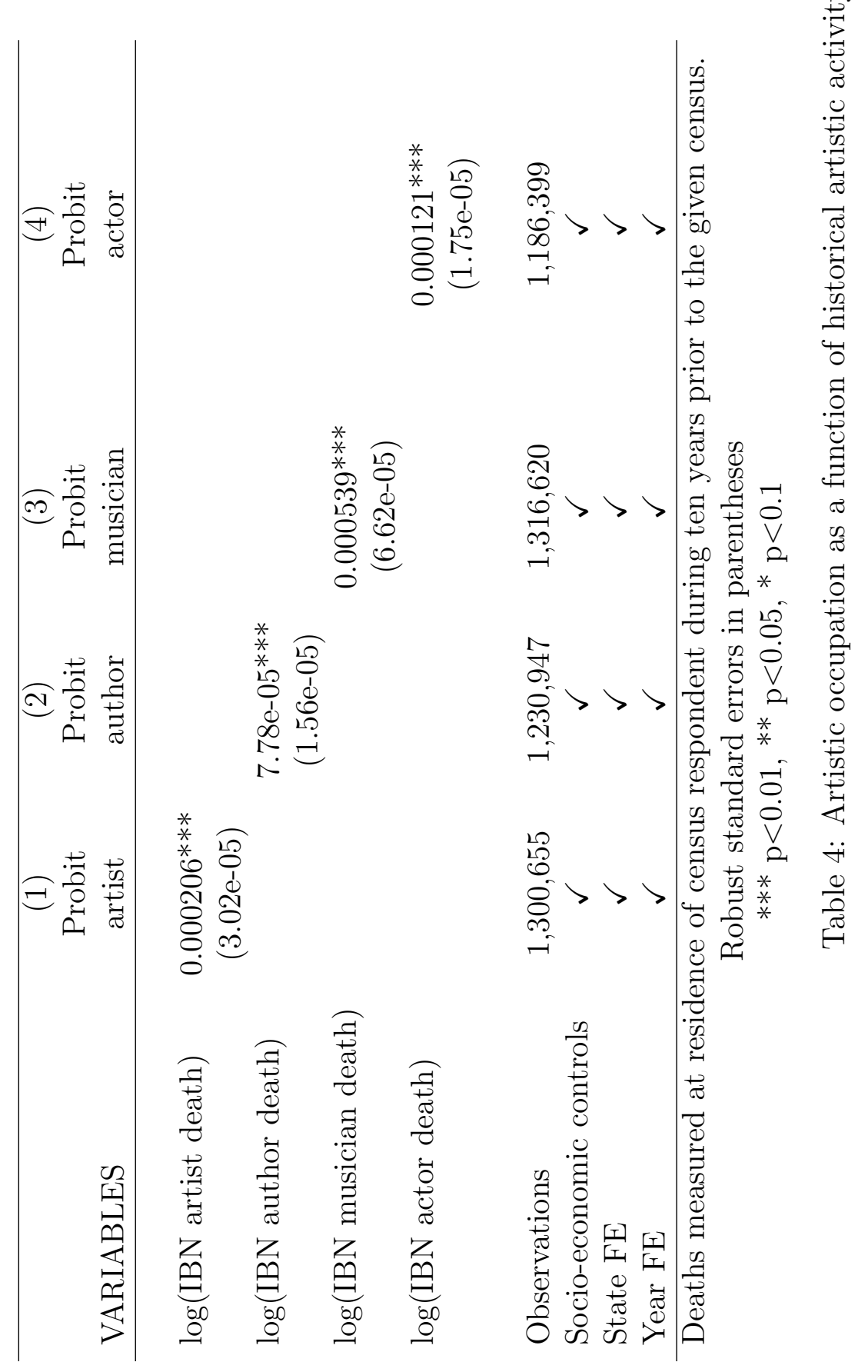




\section{$\begin{array}{ll}7 & \text { Figures }\end{array}$}

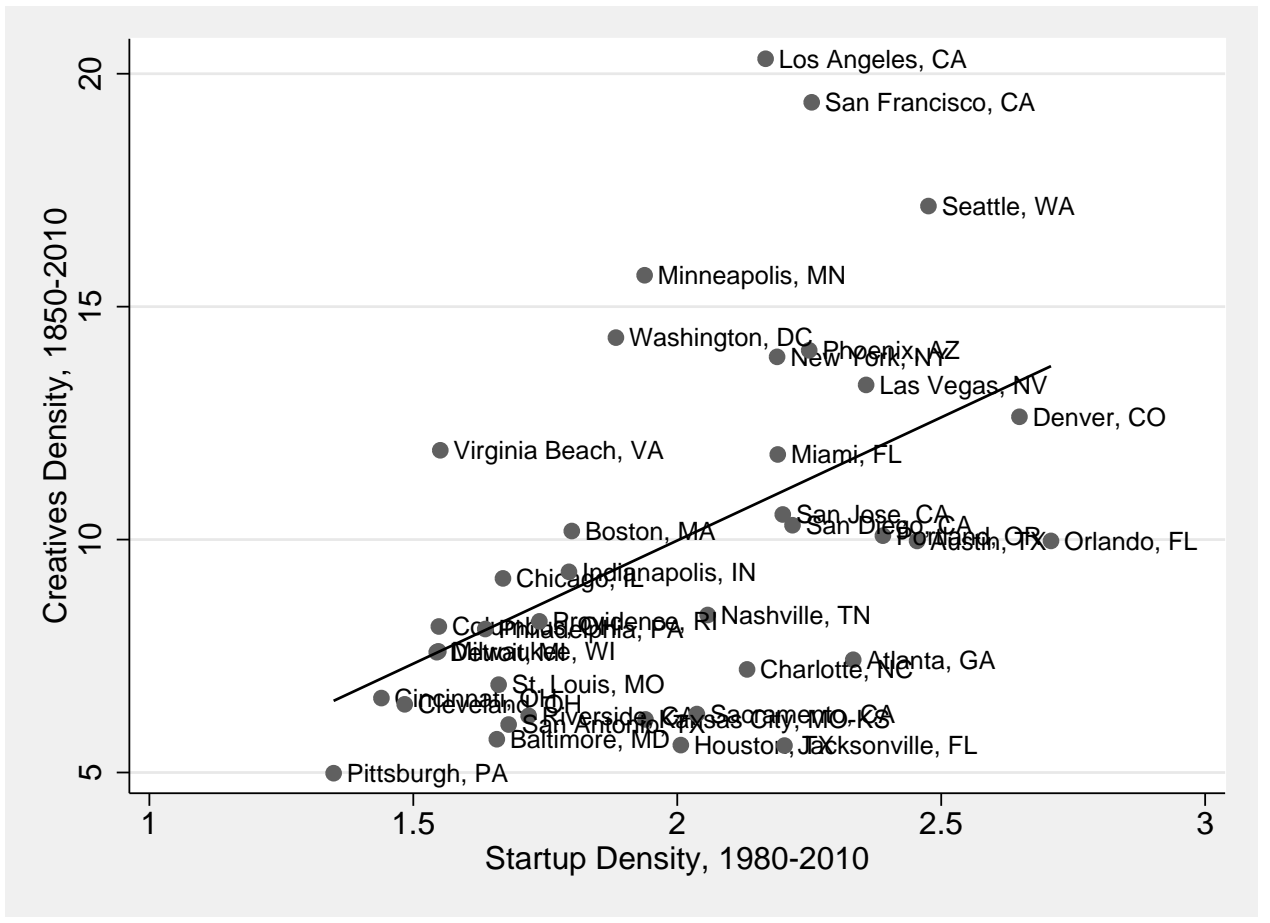

Figure 1: Creatives and Startup Densities (per 1000 people)

Sources: IPUMS (2015), Fairlie et al. (2015). Note: Creatives include artists, musicians, authors, and actors. 


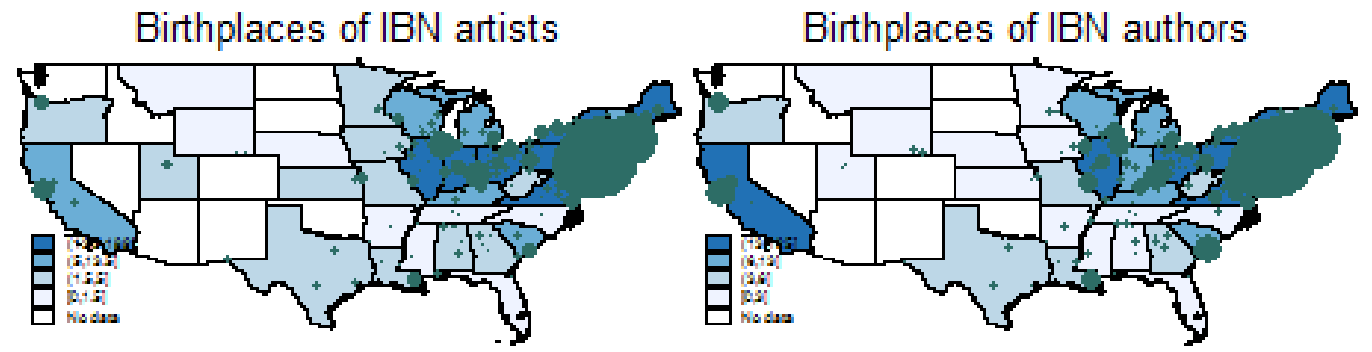

Birthplaces of IBN musicians
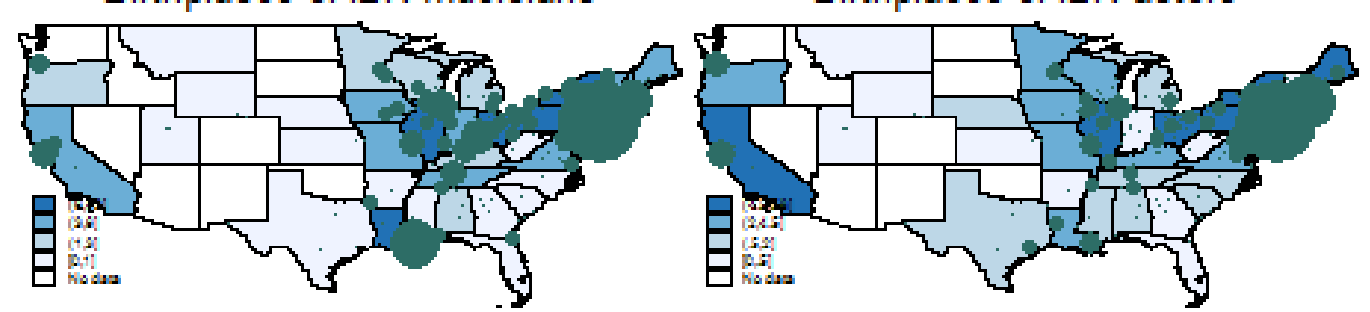

Figure 2: Birthplace of IBN creatives
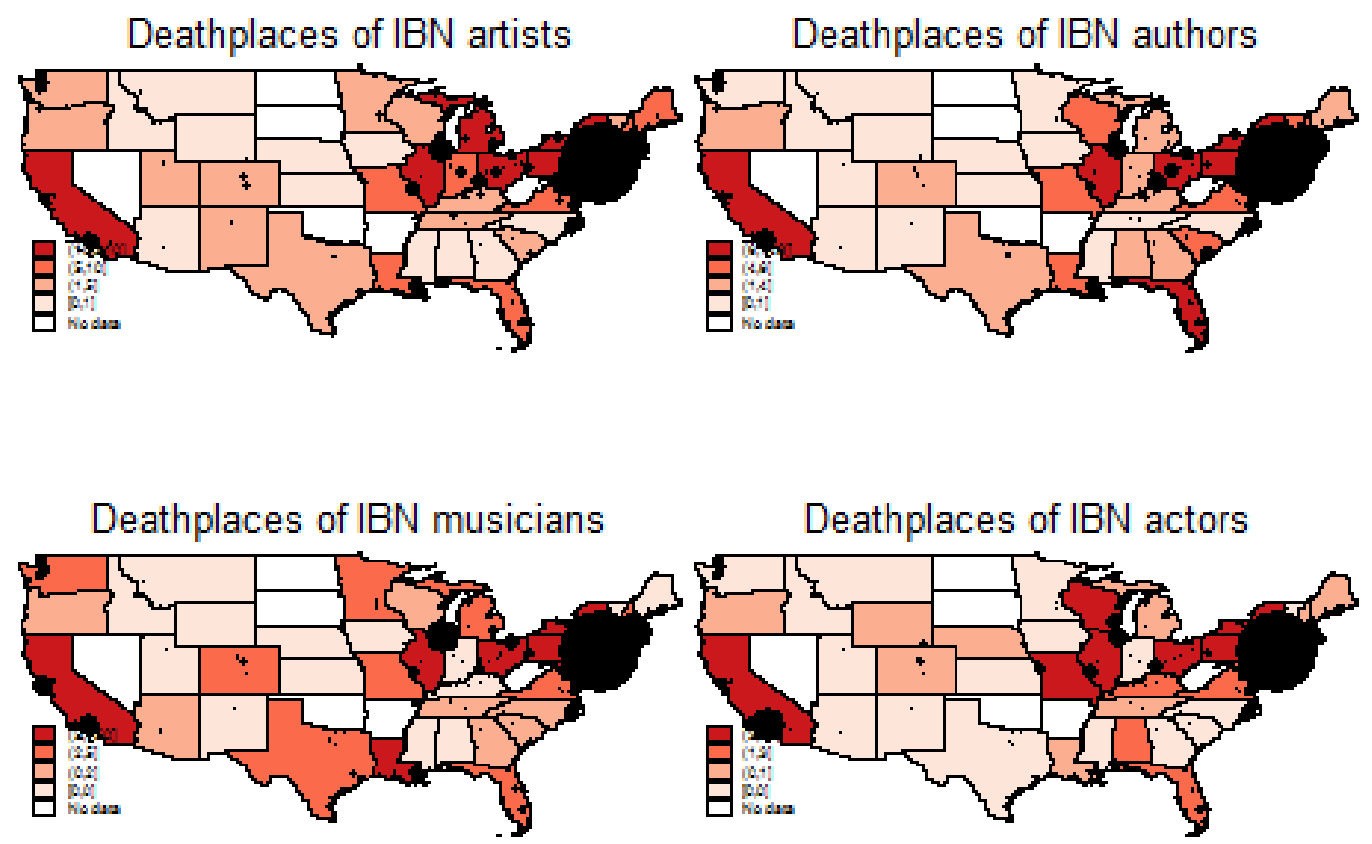

Figure 3: Deathplace of IBN creatives 

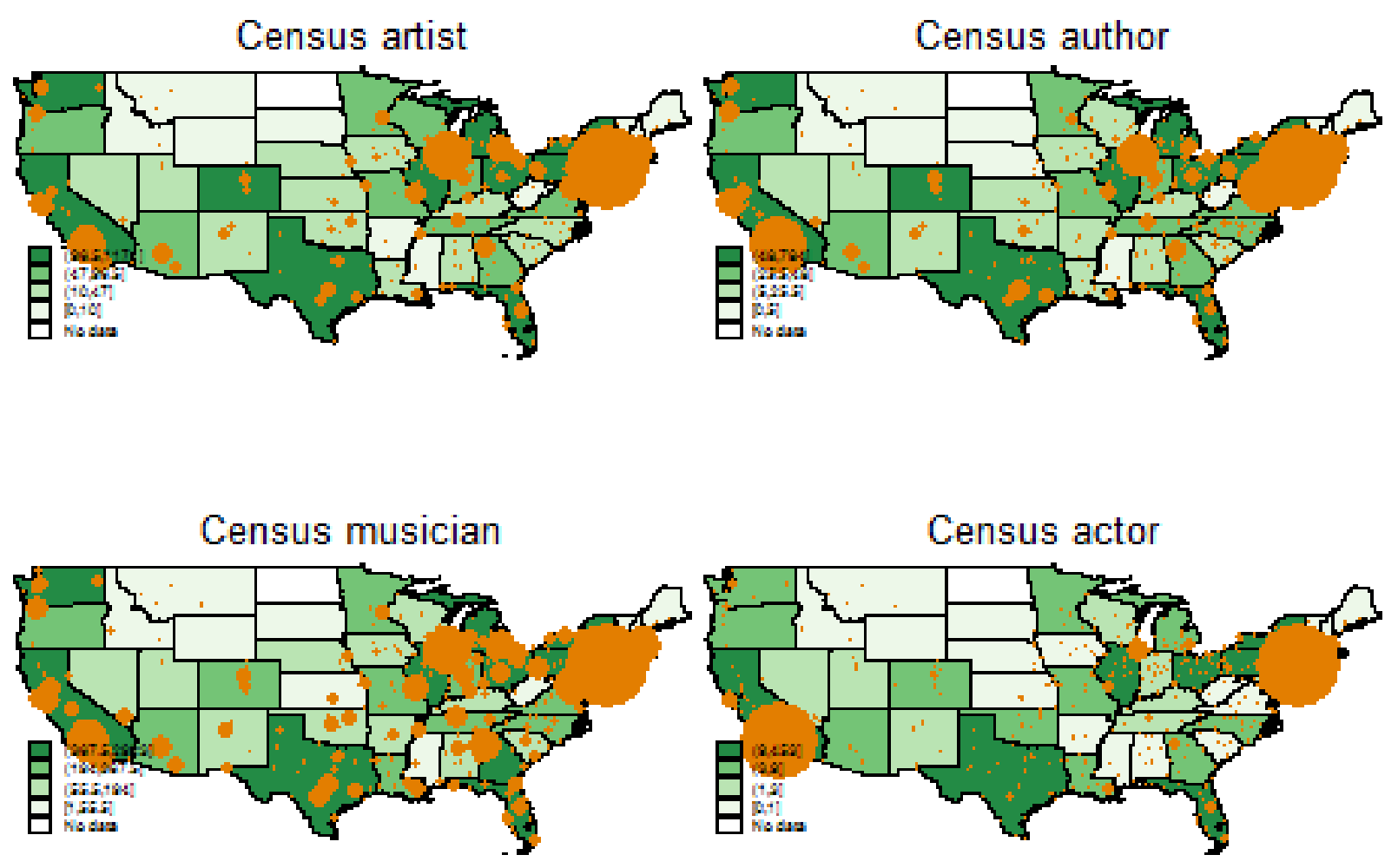

Figure 4: Location of census creatives 


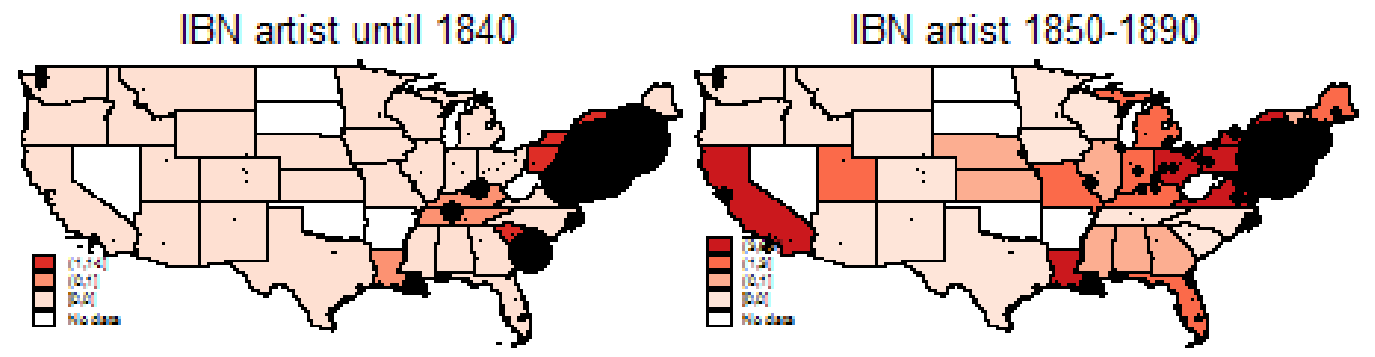

IBN artist 1900-1940

IBN artist 1950-1980

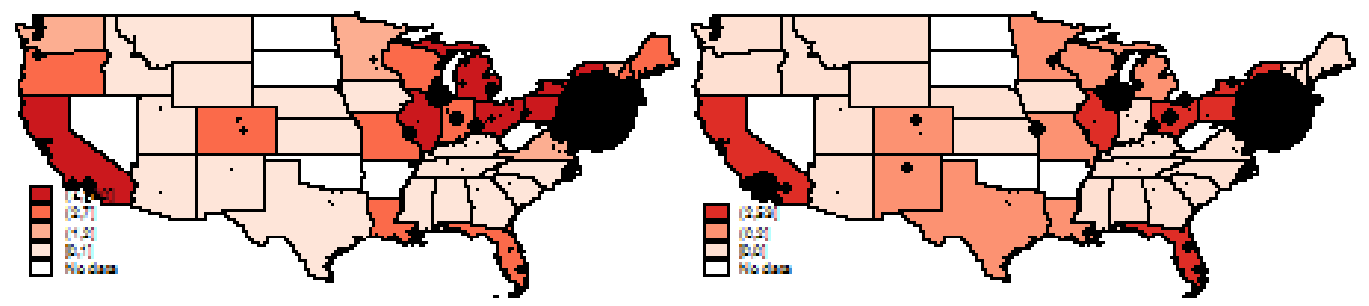

Figure 5: Geographic distribution of deaths of artists (IBN)
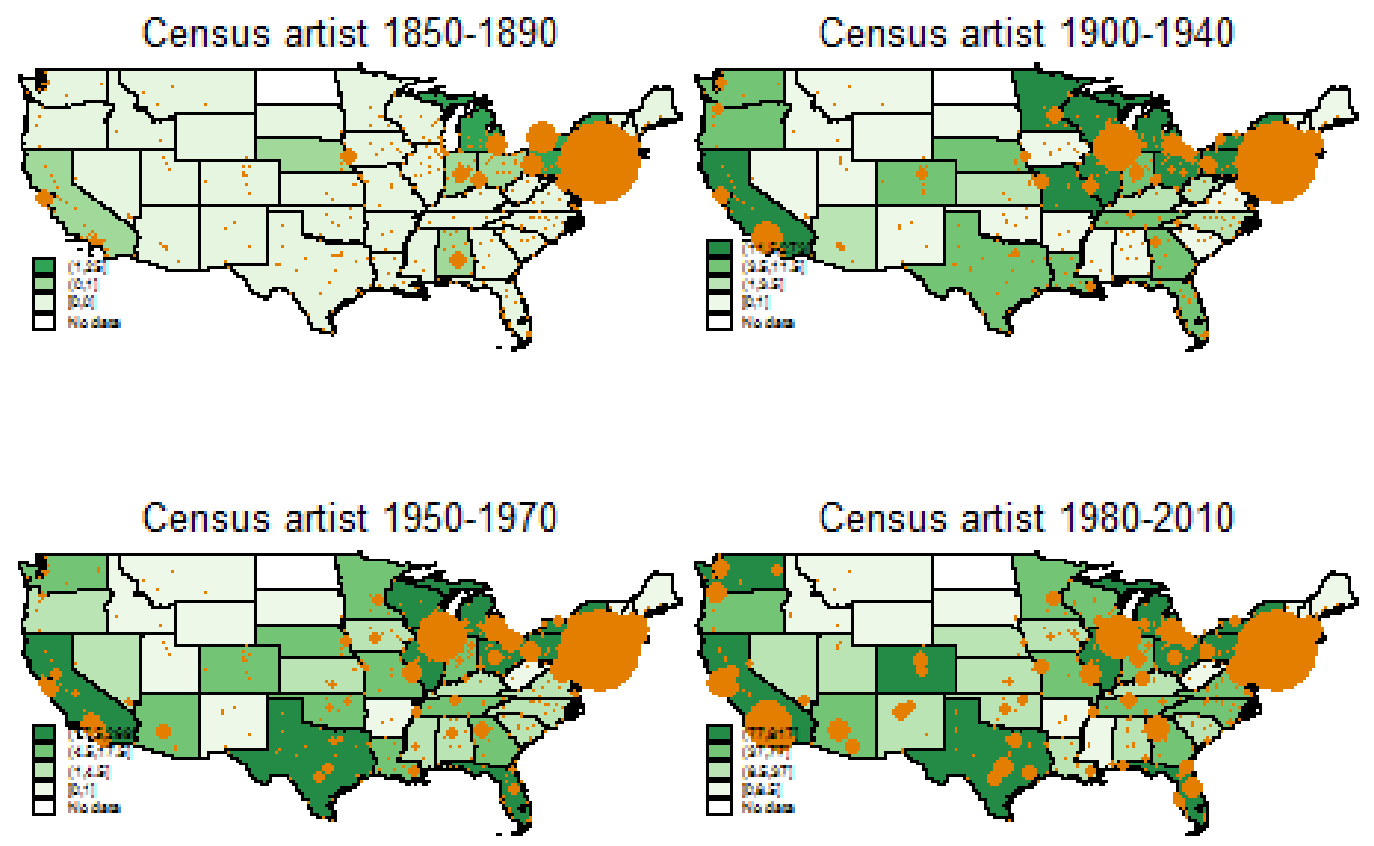

Figure 6: Geographic distribution of artists (Census) 


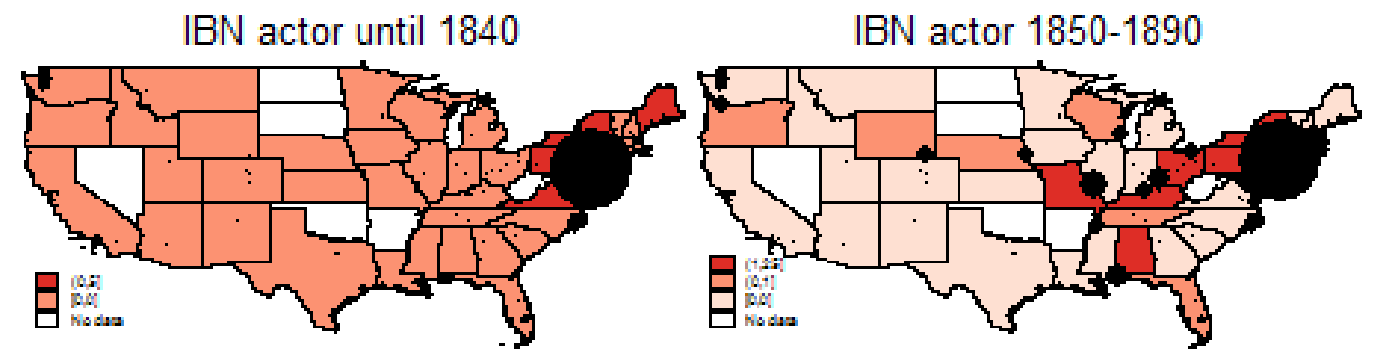

IBN actor 1900-1940

IBN actor 1950-1980

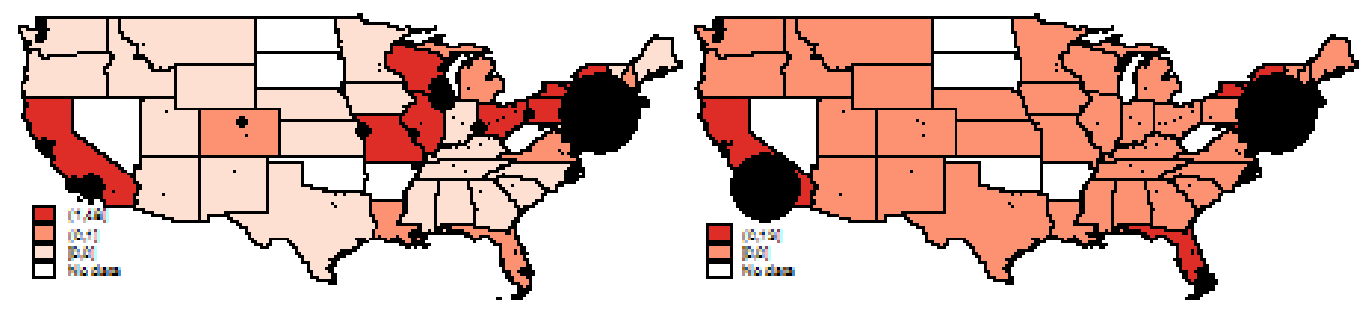

Figure 7: Geographic distribution of deaths of actors (IBN)
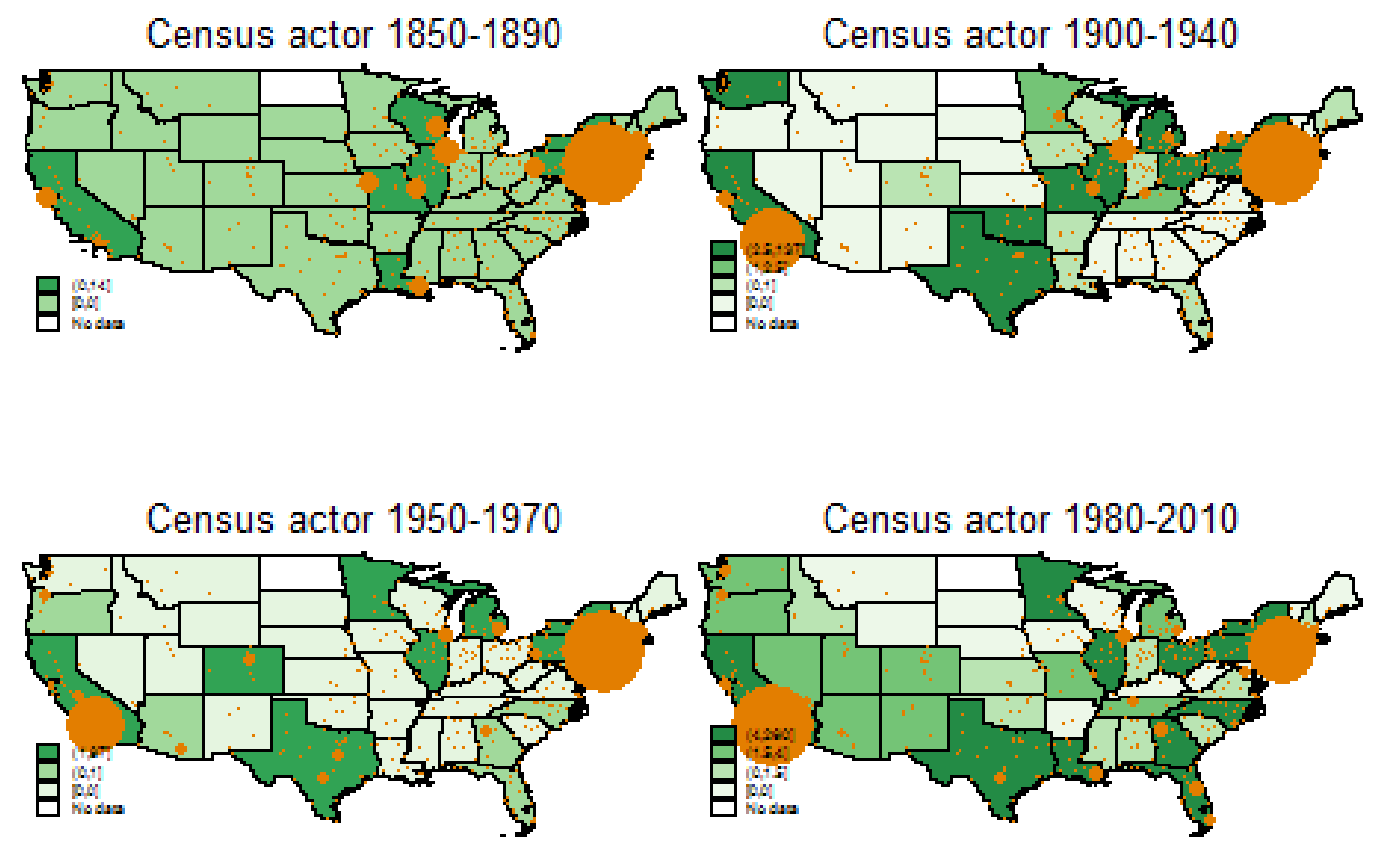

Figure 8: Geographic distribution of actors (Census) 


\section{A Online Appendix}

\section{B Graphical analysis of the socio-economic back- ground of creatives since 1850}

The regression approach presented in the paper is complemented and supported in this Appendix section with a simple analysis depicting how creatives' background change over time and differ across domains.

Figure 11 shows the share of females for the four groups of creatives studied, along with the share of females engaged in any other occupation (labeled non-creative occupations). The share of women in non-creative occupations is around $10 \%$ at the beginning of the observation window and gradually increases to around $40 \%$ by 2010 . This corresponds with the overall labor force participation of women (e.g., Goldin, 2006, Figure 1). During most of the second half of the 19th century relatively fewer female are involved in creative occupations than in other occupations. However, this changes from around 1890 when the share of females increases sharply and remains clearly above non-creative occupations before the two trends converge around 1980 for most domains.

\section{Insert Figure 11 here}

These results challenge the conventional wisdom that the arts are predominantly a male only domain. For example, previous research - which is based on prominent creatives - shows that women are practically unobservable among famous artists (e.g., O'Hagan and Borowiecki, 2010; Hellmanzik, 2010). In contrast, by looking at the average artist, as recorded by the census data, it can be observed that women have often been involved in creative occupations and that their share in these occupations - relative to males - has typically been higher than in non-creative ones. The observed patterns are also reflected anecdotally in various events that occurred in the American arts education landscape. For example, the Art Students League, founded in 1875 in New York City, saw an increasing number of women artists from the early 1890s (Weber, 2012).

Turning next to age differences, we can observe in Figure 12 that creative occupations are typically exercised by younger cohorts. One possible explanation for this is that older cohorts drop out from artistic occupations; however, the cross-section data used do not permit the investigation of the reasons behind this result in more depth. The exception is authors, who until the 1930s are on average up to ten years older than the average household head. The higher age of literary artists is possibly explained by their need to acquire a particular stock of cultural capital, before producing a literary artwork. These writers could also have been experimental innovators, who achieve success gradually and typically later in their careers (Galenson, 2007).

Insert Figure 12 here 
Next, we turn to family background variables and look first at marital status. The results presented in Figure 13 disclose how the share of singles in the American population gradually increases from levels below $5 \%$ up to about $18 \%$ by 2010 . The rise in the share of single respondents among those involved in creative occupations is considerably steeper, and by the end of our observation window about one in four creatives is single, with actors reaching the highest proportion of $40 \%$. The opposite is true for the respondents' family sizes in Figure 14. Over the last one and a half centuries, a steady decrease from about five family members to just above 2.5 can be observed. The family size of creatives is typically by at least one person smaller; however, this difference has decreased over the most recent 2-3 decades.

\section{Insert Figure 13 here}

The observed overall higher share of singles and smaller family sizes among creatives is perhaps no surprise. Both variables are related to personal or time constraints and likely limit the individual's involvement in creative activities. These results are in line with the research on cultural participation, which finds very similar patterns and attributes them to the time constraints of a person (e.g., Ateca-Amestoy, 2008). Furthermore, as we will see later, creative occupations are also usually lower paid than non-creative ones, and hence perhaps their ability to afford to get married or have a family is limited.

Turning to racial differences, it can be seen in Figure 15 that the share of whites decreases from $98 \%$ to around $80 \%$ over the time period covered. The figure indicates also that it takes almost a whole century before the first non-whites appear among artists or authors. Actors are somewhat less dominated by whites in the early 20th century and since 1980 the proportion of whites drops dramatically. Musicians are the most racially mixed group of creatives. This does not come perhaps as a surprise if one considers genres such as jazz, blues, or funk, all invented, mastered, and typically performed by blacks. These observations come though with a few shortcomings. First of all, the earliest two census editions do not include slaves, which means that the picture provided for 1850 and 1860 is incomplete. Second, non-whites who were involved in creative artistic activity over the earlier part of the period studied may not have been counted as "artists" by historical census enumerators. This could be why it looks like there are no black artists or authors until the mid-20th century. Given the fact that some of the most important American art forms were created by African Americans, one needs to be careful in the interpretation of the census data.

\section{Insert Figure 15 here}

Figure 16 provides insights into the educational attainment of the creatives covered. The censuses until 1930 provide only a dummy indicator for literacy, as presented in the left panel of the figure. It can be observed that the vast majority of creatives are literate and clearly more so than those involved in non-creative occupations. From 1940 the census data provide a more sophisticated measure of educational attainment by indicating the level of school accomplishment or the number of college years completed. Based on this information an ordinal scale between zero and 11 
has been compiled and is used in the right panel. The educational attainment is sharply increasing until about the 1990s when the increase becomes less marked. As in the pre-1940 period, the creatives have obtained significantly more education than the average non-creative worker. There are also interesting differences across the creative domains, with authors being the best educated, whereas actors are at the lower end of education attainment.

Insert Figure 16 here

\section{Additional robustness tests}

The novel long-term approach pursued in the underlying paper comes at a cost - the measurement of some of the variables has (usually slightly) changed across the 16 decades covered, while other variables are available only over limited time periods.

It is important to note that that the changes across the Census waves in the definition or measurement of some of the variables covered, have been made quite certainly independently from changes in the labor market of creatives. Furthermore, the changes go sometimes in either direction (for example, we observe both, increases and decreases in the cut-off point of age). Therefore, while the census changes may still lead to biased estimates, these biases - given the long time-period covered should not be very meaningful on average. Nonetheless, a series of robustness tests has been conducted to check on the consistency of the models estimated.

One particular change in the cut-off of a variable concerns the occupation variable (occ1950), which has been obtained in the earliest two census waves covered individuals aged $15+$, but in later editions also respondents aged $14+$ and $16+$ have been surveyed. The volatility of the cut-off point regarding age is rather small, and concerns primarily individuals who - in many cases - have not reached yet the age to become involved in a creative occupation (or perhaps even in most occupations). Nonetheless, in an attempt to check on this potential bias, one may want to drop all individuals below the age of 16 to ensure that the same age cohort is covered throughout the time period. This has been done and the results are indistinguishable from the baseline specification, which is encouraging.

\section{Additional Tables and Figures}

\section{D.1 Socio-economic background of creatives: Additional mod- els}




\begin{tabular}{|c|c|c|c|c|}
\hline & $\begin{array}{c}(1) \\
\text { Probit } \\
\text { artist }\end{array}$ & $\begin{array}{c}(2) \\
\text { Probit } \\
\text { author }\end{array}$ & $\begin{array}{c}(3) \\
\text { Probit } \\
\text { musician }\end{array}$ & $\begin{array}{l}(4) \\
\text { Probit } \\
\text { actor }\end{array}$ \\
\hline earnings & $\begin{array}{c}-1.74 \mathrm{e}-05^{* * *} \\
(7.76 \mathrm{e}-07)\end{array}$ & $\begin{array}{c}-4.97 \mathrm{e}-06^{* * *} \\
(3.15 \mathrm{e}-07)\end{array}$ & $\begin{array}{c}-4.62 \mathrm{e}-05^{* * *} \\
(1.32 \mathrm{e}-06)\end{array}$ & $\begin{array}{c}-7.63 \mathrm{e}-07^{* * *} \\
(2.34 \mathrm{e}-07)\end{array}$ \\
\hline family income & $\begin{array}{c}3.10 \mathrm{e}-06^{* * *} \\
(3.47 \mathrm{e}-07)\end{array}$ & $\begin{array}{c}1.86 \mathrm{e}-06^{* * *} \\
(1.28 \mathrm{e}-07)\end{array}$ & $\begin{array}{c}4.94 \mathrm{e}-07 \\
(7.30 \mathrm{e}-07)\end{array}$ & $\begin{array}{c}5.28 \mathrm{e}-07 * * * \\
(1.01 \mathrm{e}-07)\end{array}$ \\
\hline education & $\begin{array}{c}0.000238^{* * *} \\
(6.43 \mathrm{e}-06)\end{array}$ & $\begin{array}{c}0.000165^{* * *} \\
(4.61 \mathrm{e}-06)\end{array}$ & $\begin{array}{c}0.00115^{* * *} \\
(1.23 \mathrm{e}-05)\end{array}$ & $\begin{array}{c}2.25 \mathrm{e}-05^{* * *} \\
(2.84 \mathrm{e}-06)\end{array}$ \\
\hline female & $\begin{array}{l}6.57 \mathrm{e}-05^{*} \\
(3.88 \mathrm{e}-05)\end{array}$ & $\begin{array}{c}7.11 \mathrm{e}-05^{* * *} \\
(1.79 \mathrm{e}-05)\end{array}$ & $\begin{array}{c}0.000918^{* * *} \\
(7.40 \mathrm{e}-05)\end{array}$ & $\begin{array}{c}-3.83 \mathrm{e}-05^{* * *} \\
(1.27 \mathrm{e}-05)\end{array}$ \\
\hline age & $\begin{array}{c}9.78 \mathrm{e}-05^{* * *} \\
(6.65 \mathrm{e}-06)\end{array}$ & $\begin{array}{c}2.72 \mathrm{e}-05^{* * *} \\
(2.88 \mathrm{e}-06)\end{array}$ & $\begin{array}{c}0.000185^{* * *} \\
(1.11 \mathrm{e}-05)\end{array}$ & $\begin{array}{l}-2.55 \mathrm{e}-08 \\
(1.92 \mathrm{e}-06)\end{array}$ \\
\hline $\operatorname{age}^{2}$ & $\begin{array}{c}-1.16 \mathrm{e}-06^{* * *} \\
(7.00 \mathrm{e}-08)\end{array}$ & $\begin{array}{c}-2.92 \mathrm{e}-07 * * * \\
(2.91 \mathrm{e}-08)\end{array}$ & $\begin{array}{c}-2.24 \mathrm{e}-06^{* * *} \\
(1.11 \mathrm{e}-07)\end{array}$ & $\begin{array}{l}-1.76 \mathrm{e}-08 \\
(1.92 \mathrm{e}-08)\end{array}$ \\
\hline married & $\begin{array}{c}-0.000124^{* *} \\
(5.25 \mathrm{e}-05)\end{array}$ & $\begin{array}{c}-0.000124^{* * *} \\
(2.50 \mathrm{e}-05)\end{array}$ & $\begin{array}{c}-0.000461^{* * * *} \\
(9.59 \mathrm{e}-05)\end{array}$ & $\begin{array}{c}-6.86 \mathrm{e}-05^{* * * *} \\
(2.23 \mathrm{e}-05)\end{array}$ \\
\hline separated & $\begin{array}{c}-0.000414^{* * *} \\
(6.12 \mathrm{e}-05)\end{array}$ & $\begin{array}{c}-0.000109^{* * *} \\
(3.03 \mathrm{e}-05)\end{array}$ & $\begin{array}{c}-0.000370^{* *} \\
(0.000156)\end{array}$ & $\begin{array}{c}-7.64 \mathrm{e}-05^{* * *} \\
(1.83 \mathrm{e}-05)\end{array}$ \\
\hline divorced & $\begin{array}{c}-0.000153^{* * *} \\
(4.70 \mathrm{e}-05)\end{array}$ & $\begin{array}{c}-9.46 \mathrm{e}-05^{* * *} \\
(1.83 \mathrm{e}-05)\end{array}$ & $\begin{array}{c}6.16 \mathrm{e}-05 \\
(9.75 \mathrm{e}-05)\end{array}$ & $\begin{array}{c}-3.28 \mathrm{e}-05^{* *} \\
(1.50 \mathrm{e}-05)\end{array}$ \\
\hline widowed & $\begin{array}{c}-0.000580^{* * *} \\
(4.80 \mathrm{e}-05)\end{array}$ & $\begin{array}{c}-0.000192^{* * *} \\
(2.13 \mathrm{e}-05)\end{array}$ & $\begin{array}{c}-0.000598^{* * *} \\
(0.000120)\end{array}$ & $\begin{array}{c}-9.86 \mathrm{e}-05^{* * *} \\
(1.45 \mathrm{e}-05)\end{array}$ \\
\hline family size & $\begin{array}{c}-0.000228^{* * *} \\
(3.42 \mathrm{e}-05)\end{array}$ & $\begin{array}{c}-0.000119^{* * *} \\
(1.67 \mathrm{e}-05)\end{array}$ & $\begin{array}{c}-0.000326^{* * *} \\
(5.95 \mathrm{e}-05)\end{array}$ & $\begin{array}{c}-7.86 \mathrm{e}-05^{* * *} \\
(1.51 \mathrm{e}-05)\end{array}$ \\
\hline number children & $\begin{array}{c}5.31 \mathrm{e}-05 \\
(3.84 \mathrm{e}-05)\end{array}$ & $\begin{array}{c}6.75 \mathrm{e}-05^{* * *} \\
(1.87 \mathrm{e}-05)\end{array}$ & $\begin{array}{l}-1.93 \mathrm{e}-05 \\
(6.80 \mathrm{e}-05)\end{array}$ & $\begin{array}{c}1.78 \mathrm{e}-05 \\
(1.75 \mathrm{e}-05)\end{array}$ \\
\hline native & $\begin{array}{c}0.000435 \\
(0.000271)\end{array}$ & $\begin{array}{l}-5.05 \mathrm{e}-05 \\
(9.84 \mathrm{e}-05)\end{array}$ & $\begin{array}{c}0.000484 \\
(0.000448)\end{array}$ & $\begin{array}{l}-4.69 \mathrm{e}-05 \\
(6.12 \mathrm{e}-05)\end{array}$ \\
\hline Asian & $\begin{array}{c}-0.000191^{* * *} \\
(6.82 \mathrm{e}-05)\end{array}$ & $\begin{array}{c}-0.000232^{* * *} \\
(1.58 \mathrm{e}-05)\end{array}$ & $\begin{array}{c}-0.00145^{* * *} \\
(9.75 \mathrm{e}-05)\end{array}$ & $\begin{array}{c}-0.000114^{* * *} \\
(1.19 \mathrm{e}-05)\end{array}$ \\
\hline other & $\begin{array}{c}-0.000267^{* * *} \\
(9.17 \mathrm{e}-05)\end{array}$ & $\begin{array}{c}-0.000221^{* * *} \\
(2.78 \mathrm{e}-05)\end{array}$ & $\begin{array}{c}-0.000510^{* * *} \\
(0.000185)\end{array}$ & $\begin{array}{c}-7.12 \mathrm{e}-05^{* * *} \\
(2.18 \mathrm{e}-05)\end{array}$ \\
\hline mixed & $\begin{array}{c}8.26 \mathrm{e}-05 \\
(0.000162)\end{array}$ & $\begin{array}{l}-1.61 \mathrm{e}-05 \\
(5.60 \mathrm{e}-05)\end{array}$ & $\begin{array}{c}0.000117 \\
(0.000263)\end{array}$ & $\begin{array}{c}0.000156^{* *} \\
(6.41 \mathrm{e}-05)\end{array}$ \\
\hline Observations & $3,078,967$ & $3,069,098$ & $3,086,265$ & $1,735,187$ \\
\hline State FE & $\checkmark$ & $\checkmark$ & $\checkmark$ & $\checkmark$ \\
\hline Year FE & $\checkmark$ & $\checkmark$ & $\checkmark$ & $\checkmark$ \\
\hline
\end{tabular}

Robust standard errors in parentheses *** $\mathrm{p}<0.01,{ }^{*} * \mathrm{p}<0.05,{ }^{*} \mathrm{p}<0.1$

Table 5: Socio-economic background of creatives: Education and income 


\begin{tabular}{|c|c|c|c|c|}
\hline & $\begin{array}{c}(1) \\
\text { Probit } \\
\text { artist }\end{array}$ & $\begin{array}{c}(2) \\
\text { Probit } \\
\text { author }\end{array}$ & $\begin{array}{c}(3) \\
\text { Probit } \\
\text { musician }\end{array}$ & $\begin{array}{c}(4) \\
\text { Probit } \\
\text { actor }\end{array}$ \\
\hline female & $\begin{array}{c}0.000170^{* * *} \\
(6.44 \mathrm{e}-05)\end{array}$ & $\begin{array}{c}2.11 \mathrm{e}-05 \\
(2.18 \mathrm{e}-05)\end{array}$ & $\begin{array}{c}0.000457^{* * *} \\
(0.000133)\end{array}$ & $\begin{array}{c}-6.87 \mathrm{e}-05^{* * *} \\
(2.18 \mathrm{e}-05)\end{array}$ \\
\hline age & $\begin{array}{c}7.60 \mathrm{e}-05^{* * *} \\
(1.06 \mathrm{e}-05)\end{array}$ & $\begin{array}{c}3.39 \mathrm{e}-05^{* * *} \\
(4.19 \mathrm{e}-06)\end{array}$ & $\begin{array}{c}0.000179 * * * \\
(1.98 \mathrm{e}-05)\end{array}$ & $\begin{array}{c}5.88 \mathrm{e}-07 \\
(3.45 \mathrm{e}-06)\end{array}$ \\
\hline $\operatorname{age}^{2}$ & $\begin{array}{c}-9.97 \mathrm{e}-07^{* * *} \\
(1.13 \mathrm{e}-07)\end{array}$ & $\begin{array}{c}-3.82 \mathrm{e}-07^{* * *} \\
(4.47 \mathrm{e}-08)\end{array}$ & $\begin{array}{c}-2.41 \mathrm{e}-06^{* * *} \\
(2.04 \mathrm{e}-07)\end{array}$ & $\begin{array}{l}-5.39 \mathrm{e}-08 \\
(3.55 \mathrm{e}-08)\end{array}$ \\
\hline separated & $\begin{array}{c}-0.000262^{*} \\
(0.000156)\end{array}$ & $\begin{array}{c}-0.000158^{* * *} \\
(3.13 \mathrm{e}-05)\end{array}$ & $\begin{array}{c}-0.000585^{* *} \\
(0.000286)\end{array}$ & $\begin{array}{l}-9.78 \mathrm{e}-05^{*} \\
(5.82 \mathrm{e}-05)\end{array}$ \\
\hline divorced & $\begin{array}{c}0.000281^{* *} \\
(0.000126)\end{array}$ & $\begin{array}{c}-0.000103^{* * *} \\
(2.51 \mathrm{e}-05)\end{array}$ & $\begin{array}{l}0.000524^{* *} \\
(0.000215)\end{array}$ & $\begin{array}{c}0.000237^{* * *} \\
(7.91 \mathrm{e}-05)\end{array}$ \\
\hline widowed & $\begin{array}{c}-0.000453^{* * *} \\
(9.37 \mathrm{e}-05)\end{array}$ & $\begin{array}{c}-0.000198^{* * *} \\
(2.64 \mathrm{e}-05)\end{array}$ & $\begin{array}{c}-0.00149^{* * *} \\
(0.000175)\end{array}$ & $\begin{array}{c}2.46 \mathrm{e}-05 \\
(4.46 \mathrm{e}-05)\end{array}$ \\
\hline single & $\begin{array}{c}0.000538^{* * *} \\
(0.000112)\end{array}$ & $\begin{array}{l}-2.21 \mathrm{e}-05 \\
(2.75 \mathrm{e}-05)\end{array}$ & $\begin{array}{c}0.000887^{* * *} \\
(0.000187)\end{array}$ & $\begin{array}{c}0.000132^{* * * *} \\
(4.42 \mathrm{e}-05)\end{array}$ \\
\hline family size & $\begin{array}{c}-0.000229^{* * *} \\
(4.45 \mathrm{e}-05)\end{array}$ & $\begin{array}{c}-0.000139^{* * *} \\
(2.13 \mathrm{e}-05)\end{array}$ & $\begin{array}{c}-0.000466^{* * *} \\
(7.78 \mathrm{e}-05)\end{array}$ & $\begin{array}{c}-3.36 \mathrm{e}-05^{* *} \\
(1.54 \mathrm{e}-05)\end{array}$ \\
\hline number children & $\begin{array}{l}-8.38 \mathrm{e}-05 \\
(5.20 \mathrm{e}-05)\end{array}$ & $\begin{array}{c}8.21 \mathrm{e}-06 \\
(2.53 \mathrm{e}-05)\end{array}$ & $\begin{array}{c}-0.000302^{* * *} \\
(9.25 \mathrm{e}-05)\end{array}$ & $\begin{array}{c}-7.16 \mathrm{e}-05^{* * *} \\
(1.86 \mathrm{e}-05)\end{array}$ \\
\hline black & $\begin{array}{c}-0.00125^{* * *} \\
(4.75 \mathrm{e}-05)\end{array}$ & $\begin{array}{c}-0.000323^{* * *} \\
(2.37 \mathrm{e}-05)\end{array}$ & $\begin{array}{c}-0.00142^{* * *} \\
(0.000120)\end{array}$ & $\begin{array}{c}-0.000148^{* * * *} \\
(2.35 \mathrm{e}-05)\end{array}$ \\
\hline native & $\begin{array}{l}-0.000408 \\
(0.000307)\end{array}$ & $\begin{array}{c}-0.000176^{* * *} \\
(6.70 \mathrm{e}-05)\end{array}$ & $\begin{array}{l}-0.000204 \\
(0.000757)\end{array}$ & $\begin{array}{c}-0.000136^{*} \\
(8.07 \mathrm{e}-05)\end{array}$ \\
\hline Asian & $\begin{array}{c}-0.000388^{* * *} \\
(9.98 \mathrm{e}-05)\end{array}$ & $\begin{array}{c}-0.000207^{* * *} \\
(2.05 \mathrm{e}-05)\end{array}$ & $\begin{array}{c}-0.00194^{* * *} \\
(0.000166)\end{array}$ & $\begin{array}{c}-0.000198 * * * \\
(2.16 \mathrm{e}-05)\end{array}$ \\
\hline other & $\begin{array}{c}-0.000867^{* * *} \\
(6.70 \mathrm{e}-05)\end{array}$ & $\begin{array}{c}-0.000276^{* * *} \\
(2.06 \mathrm{e}-05)\end{array}$ & $\begin{array}{c}-0.00245^{* * *} \\
(0.000155)\end{array}$ & $\begin{array}{c}-0.000200^{* * *} \\
(2.15 \mathrm{e}-05)\end{array}$ \\
\hline mixed & $\begin{array}{l}-0.000241 \\
(0.000218)\end{array}$ & $\begin{array}{c}-0.000199^{* * *} \\
(3.07 \mathrm{e}-05)\end{array}$ & $\begin{array}{l}-0.000538 \\
(0.000435)\end{array}$ & $\begin{array}{c}6.34 \mathrm{e}-05 \\
(8.04 \mathrm{e}-05)\end{array}$ \\
\hline migrant & $\begin{array}{c}0.000245^{* * *} \\
(5.26 \mathrm{e}-05)\end{array}$ & $\begin{array}{c}0.000149^{* * *} \\
(2.05 \mathrm{e}-05)\end{array}$ & $\begin{array}{c}0.000970 * * * \\
(0.000103)\end{array}$ & $\begin{array}{c}0.000116^{* * *} \\
(2.13 \mathrm{e}-05)\end{array}$ \\
\hline $\log ($ city population $)$ & $\begin{array}{c}0.000234^{* * *} \\
(2.40 \mathrm{e}-05)\end{array}$ & $\begin{array}{c}0.000105^{* * *} \\
(1.13 \mathrm{e}-05)\end{array}$ & $\begin{array}{c}0.000385^{* * *} \\
(4.36 \mathrm{e}-05)\end{array}$ & $\begin{array}{c}0.000104^{* * *} \\
(1.18 \mathrm{e}-05)\end{array}$ \\
\hline Observations & $1,324,794$ & $1,313,696$ & $1,330,482$ & 910,614 \\
\hline State FE & $\checkmark$ & $\checkmark$ & $\checkmark$ & $\checkmark$ \\
\hline Year FE & $\checkmark$ & $\checkmark$ & $\checkmark$ & $\checkmark$ \\
\hline
\end{tabular}

Robust standard errors in parentheses *** $\mathrm{p}<0.01, * * \mathrm{p}<0.05, * \mathrm{p}<0.1$

Table 6: Socio-economic background of creatives: City size and migrants 


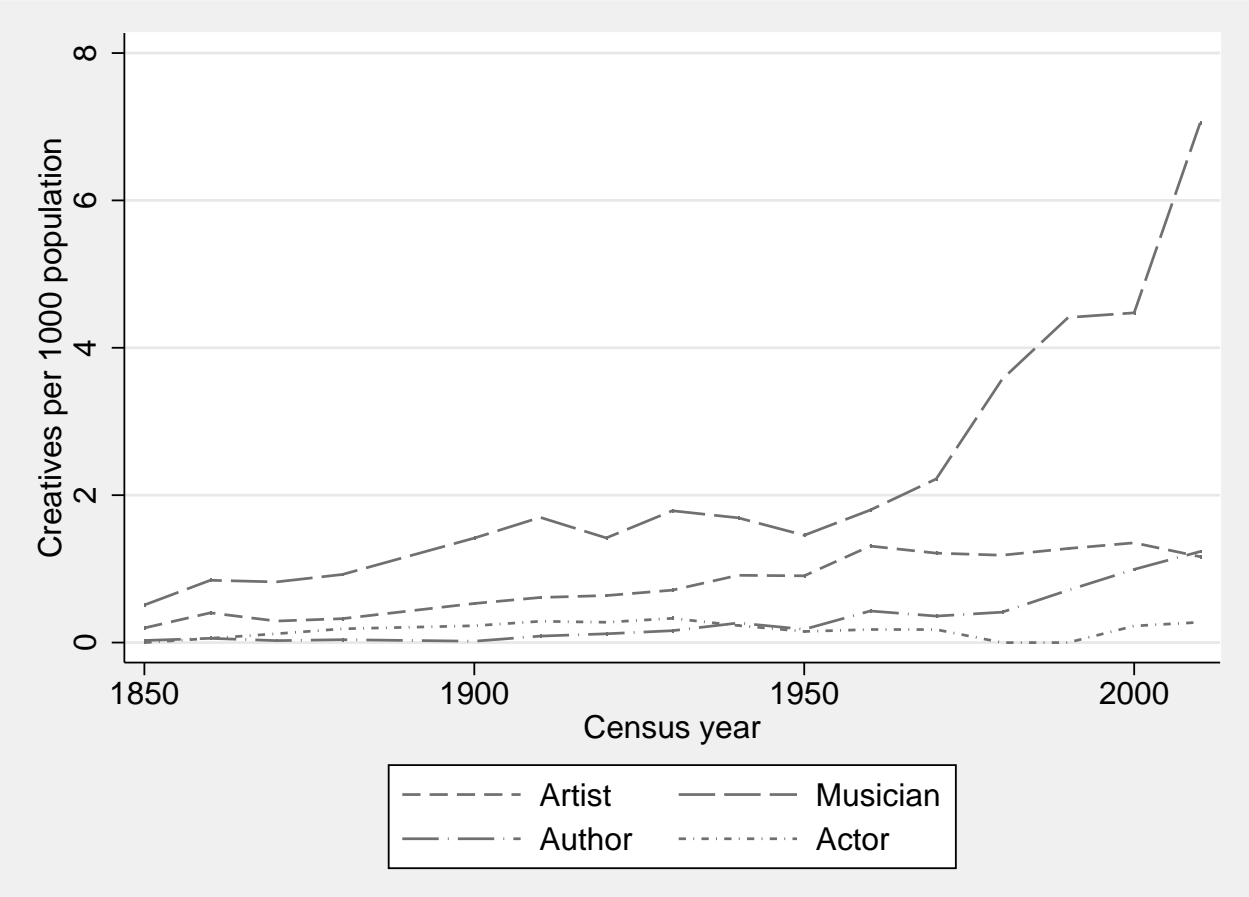

Figure 9: Share of household heads with artistic occupations

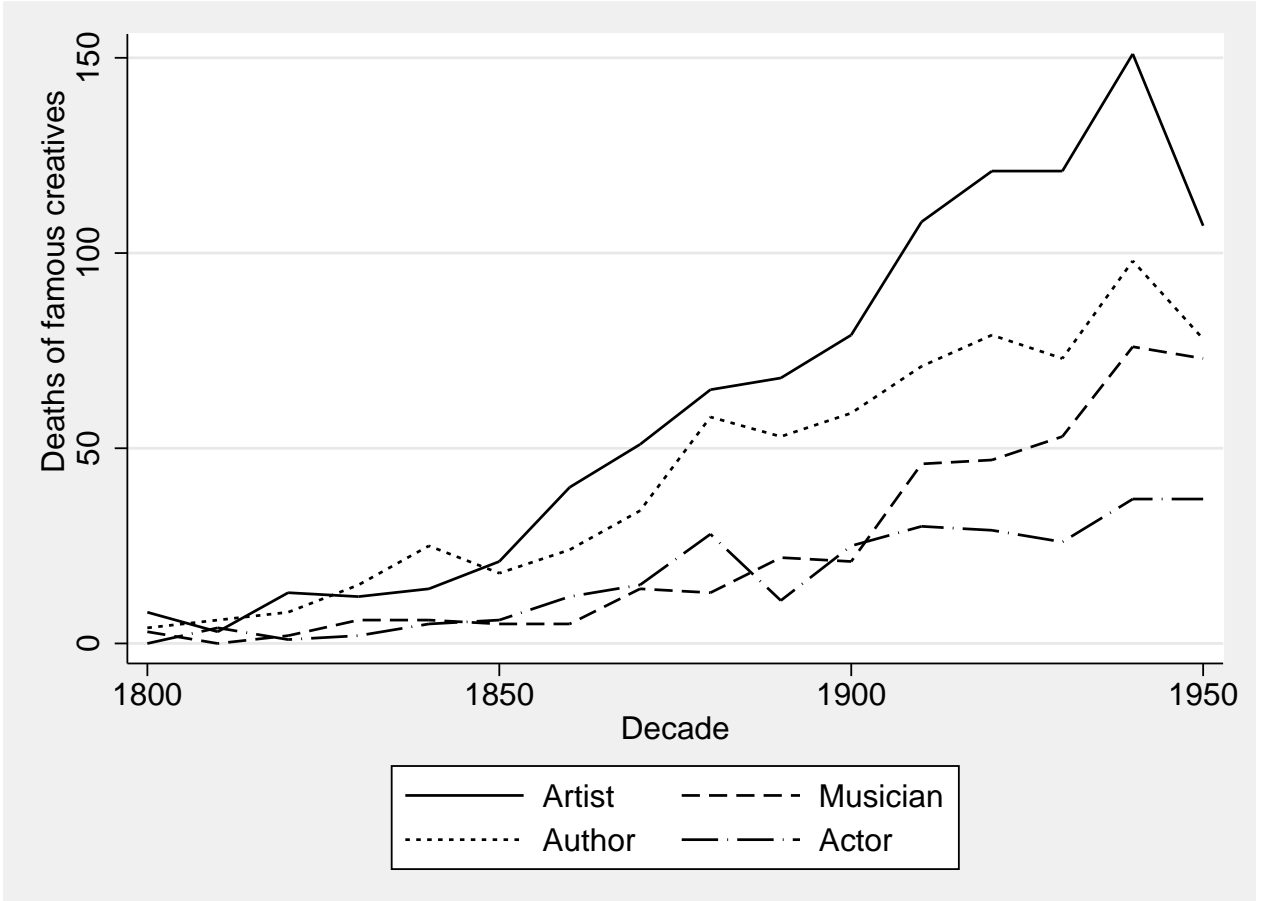

Figure 10: Deaths of famous creatives (IBN) by occupation 


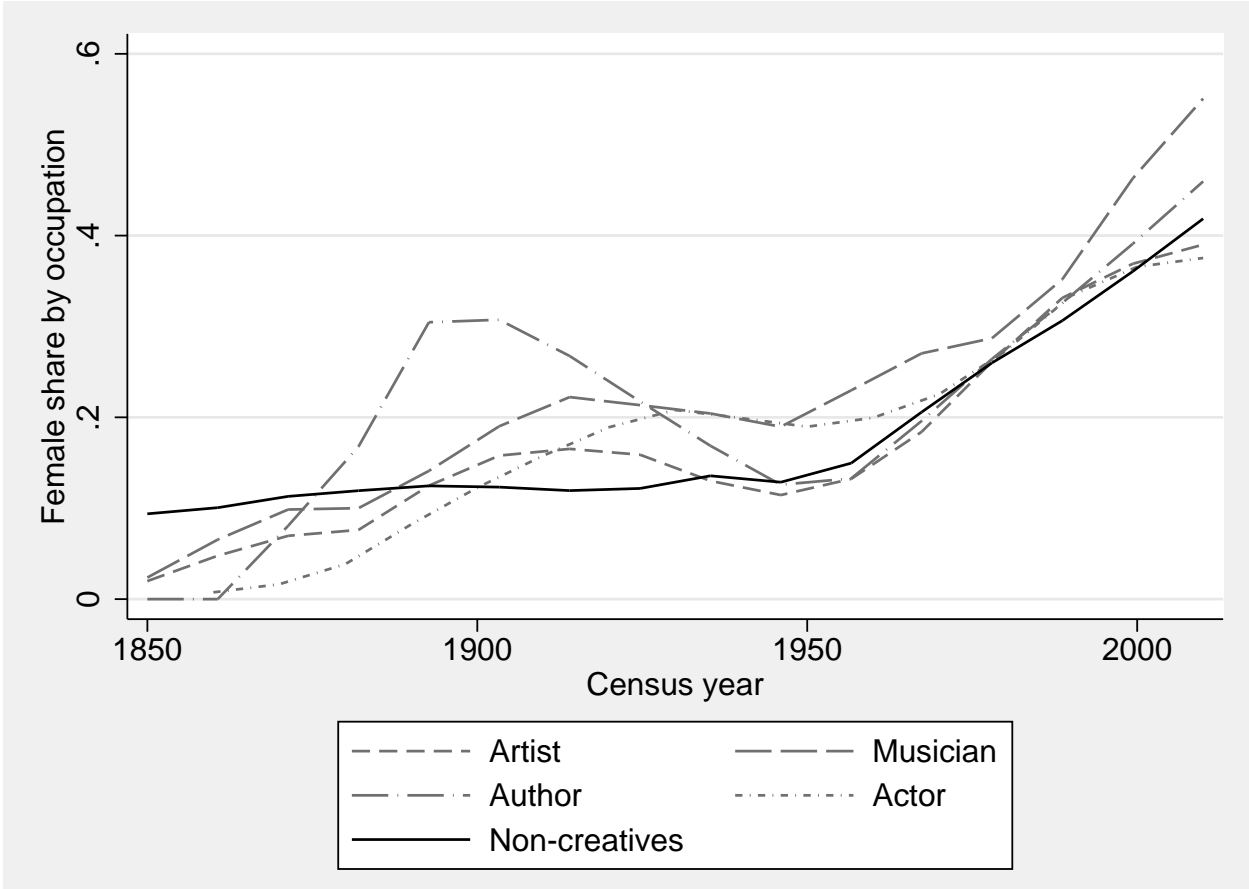

Figure 11: Female share by occupation

Note: The "All occupations" category provides the average for all household heads.

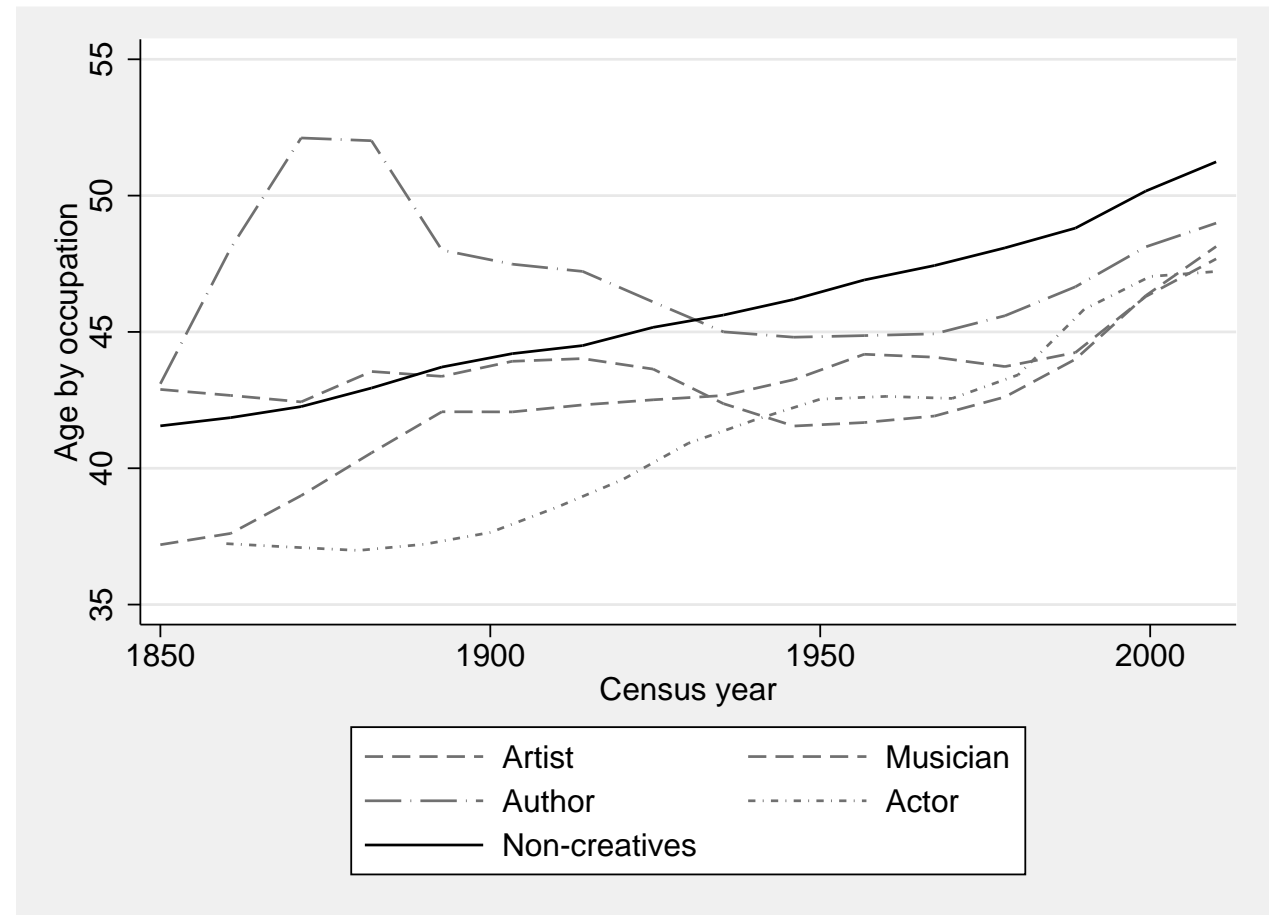

Figure 12: Age by occupation

Note: See Figure 11 


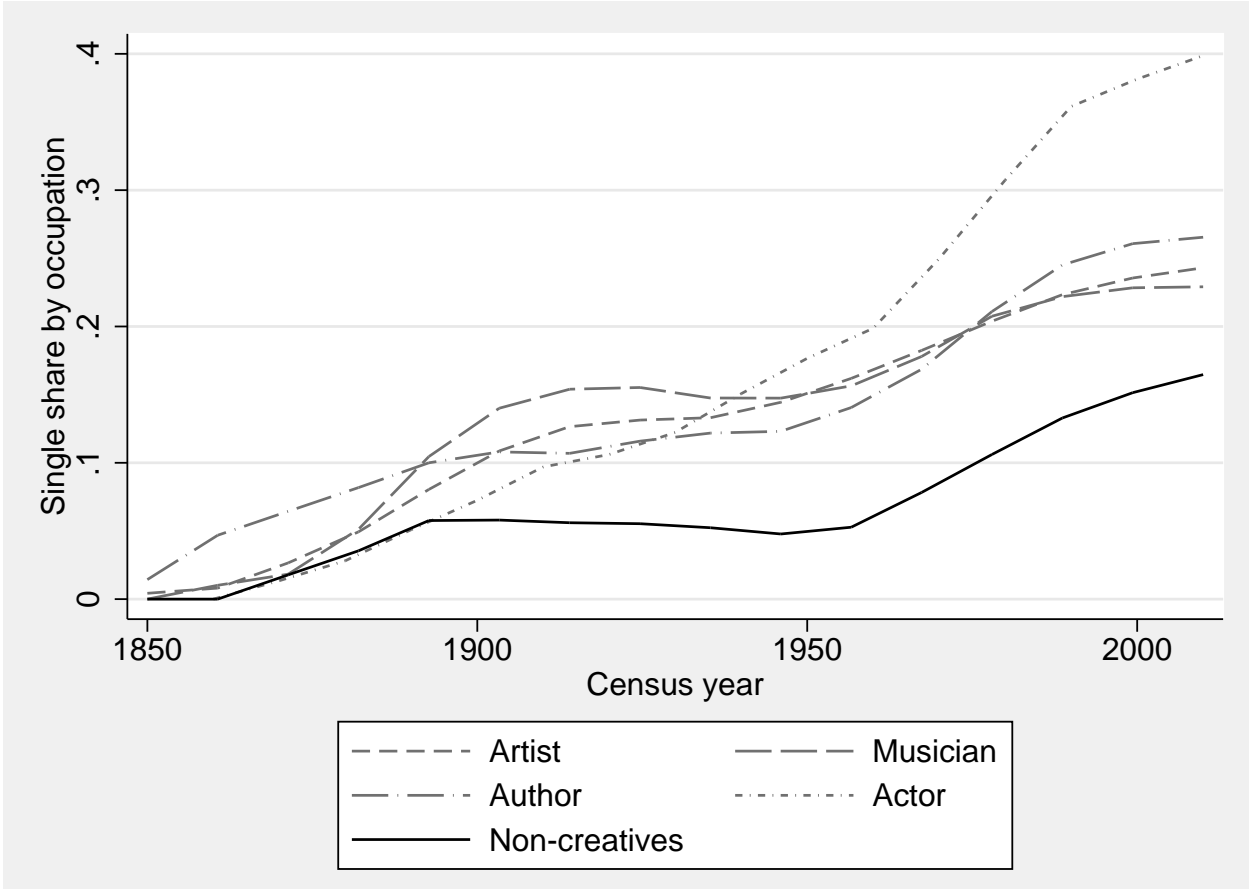

Figure 13: Being single by occupation Note: See Figure 11

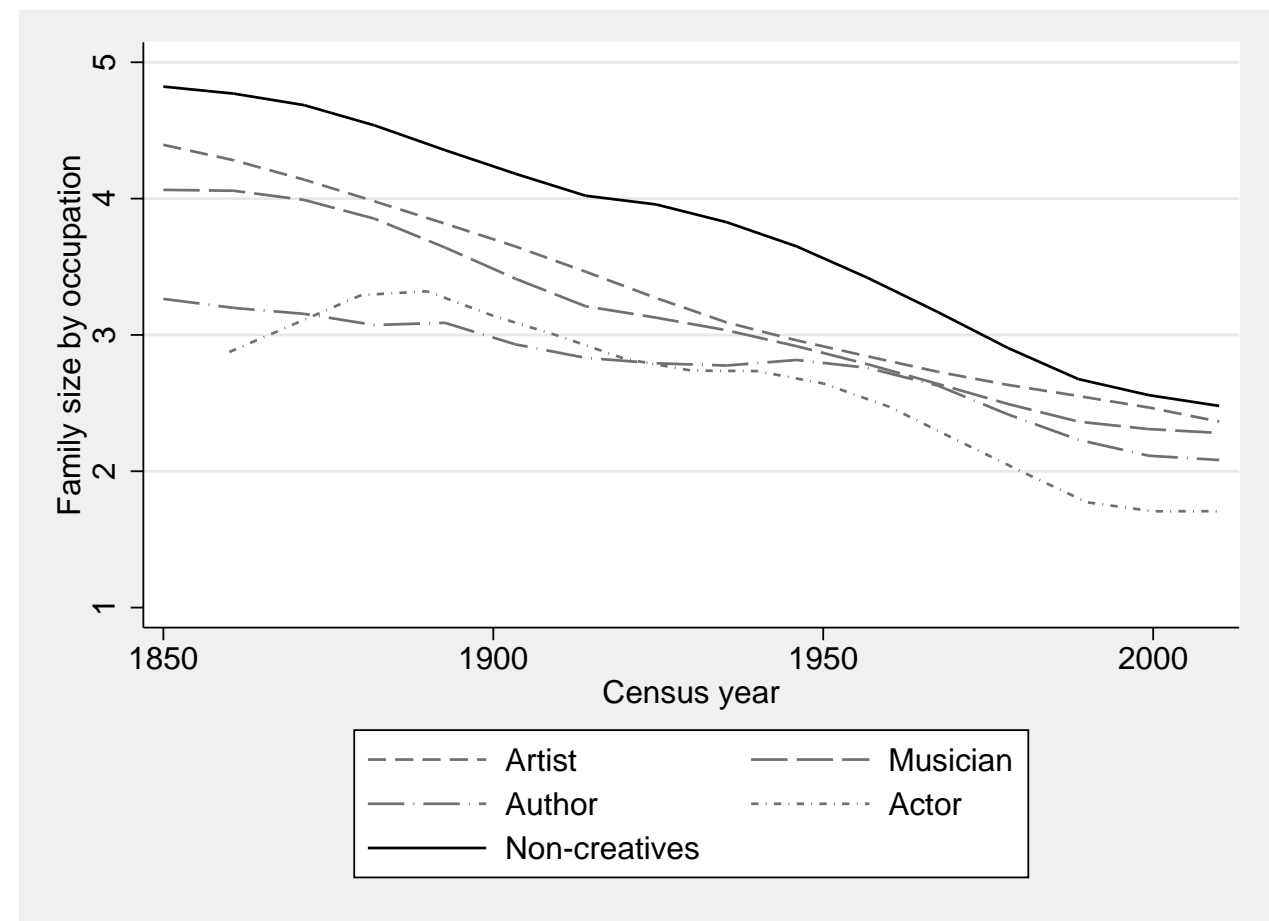

Figure 14: Family size by occupation Note: See Figure 11 


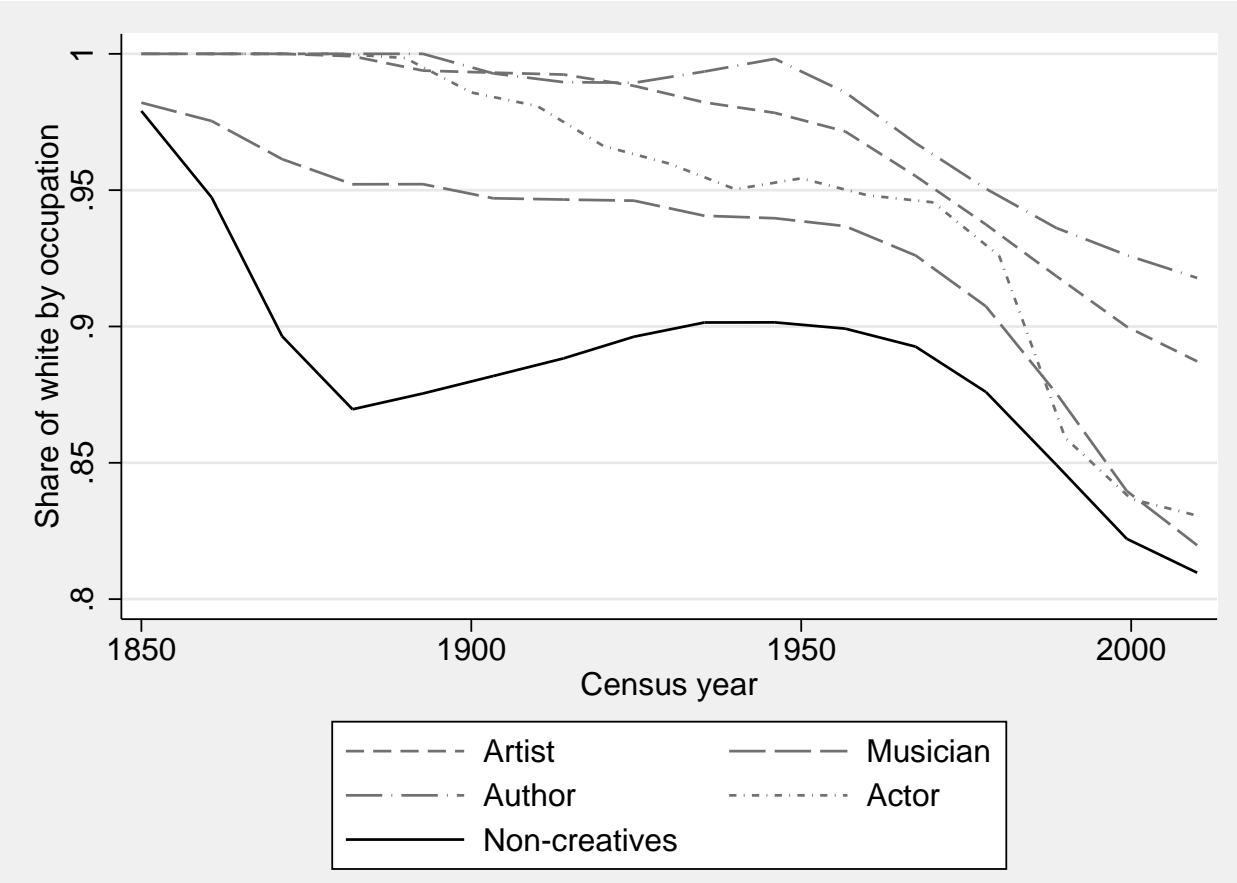

Figure 15: White by occupation Note: See Figure 11
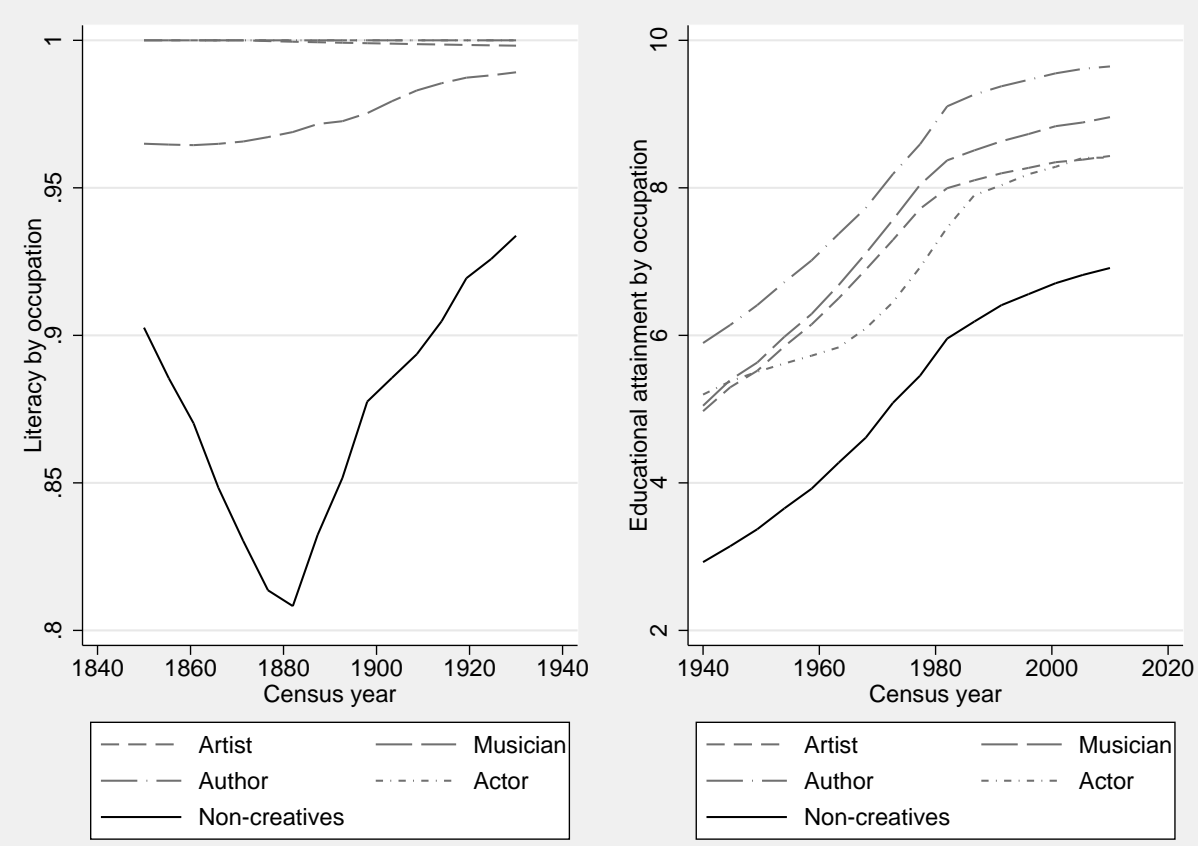

Figure 16: Educational attainment by occupation Note: See Figure 11 

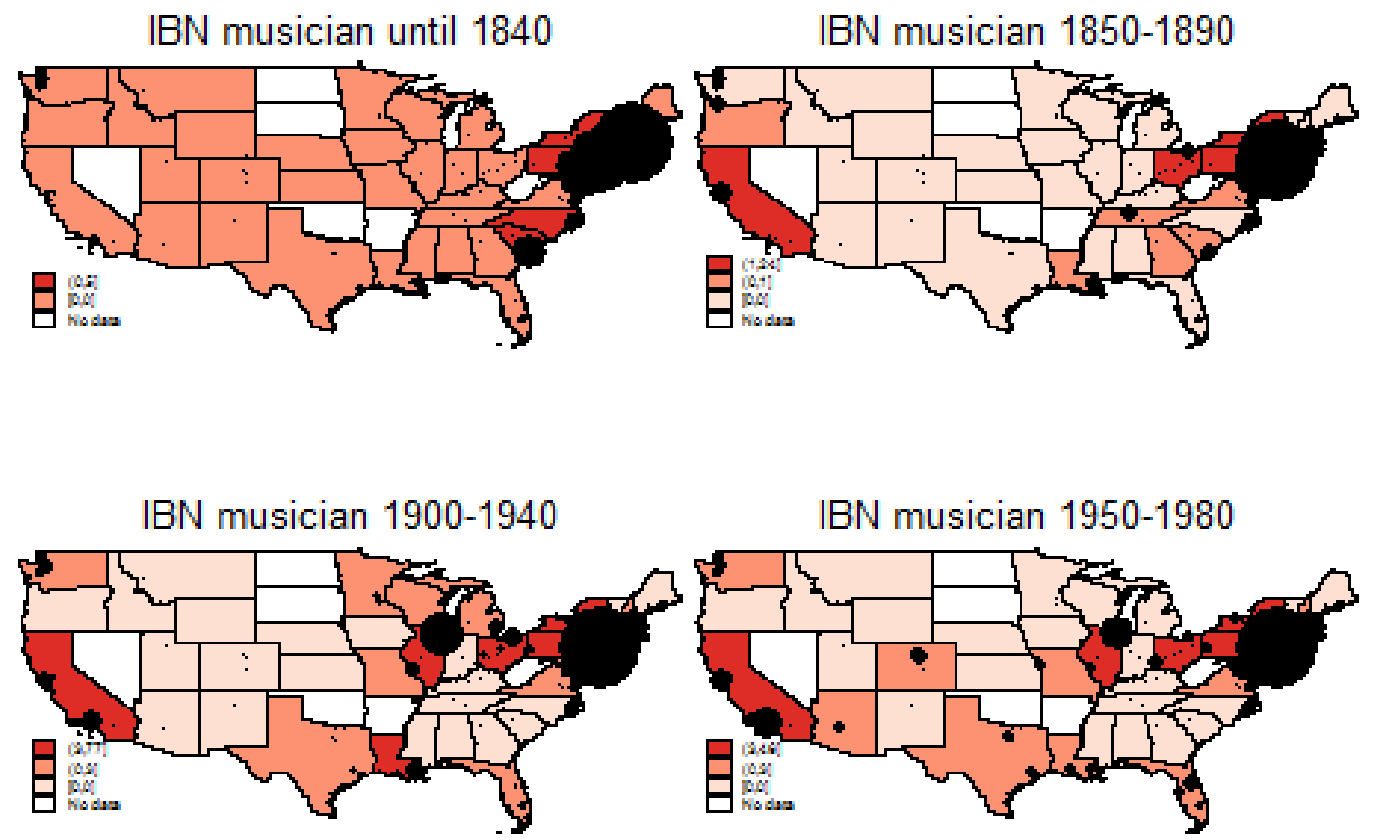

Figure 17: Geographic distribution of deaths of musicians (IBN)
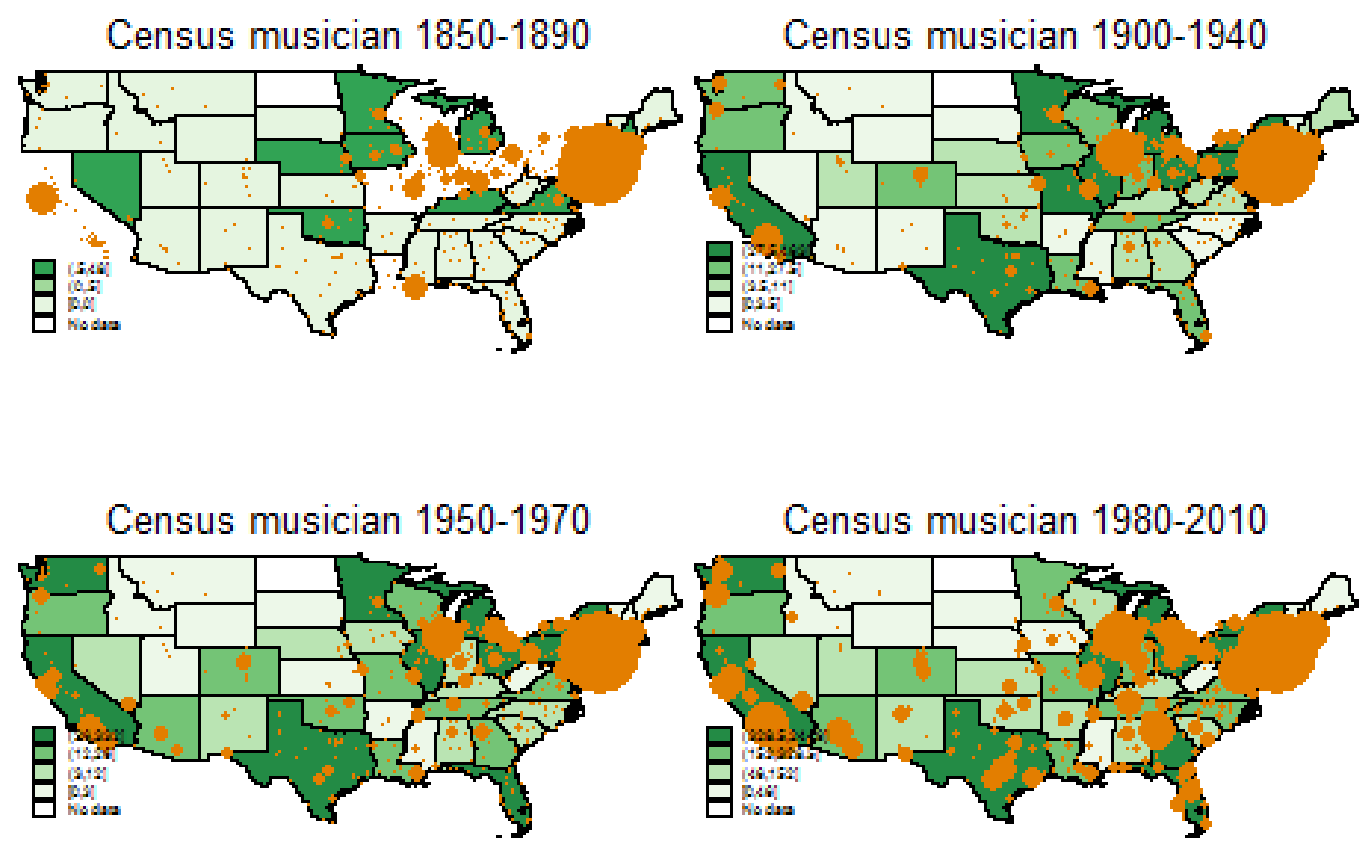

Figure 18: Geographic distribution of musicians (Census) 


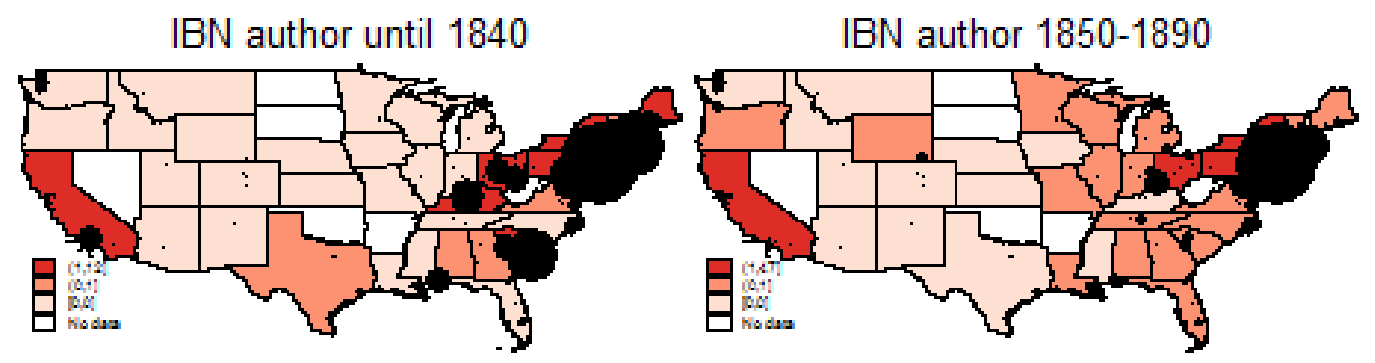

IBN author 1900-1940

IBN author 1950-1980

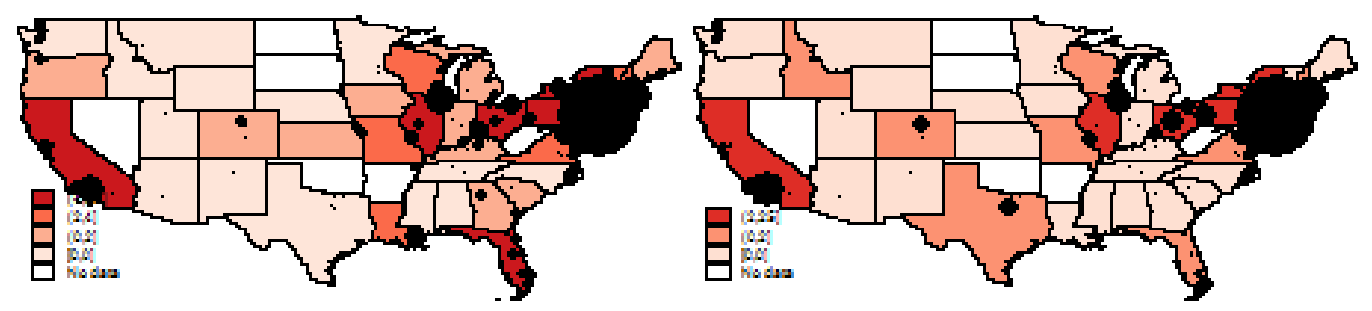

Figure 19: Geographic distribution of deaths of authors (IBN) 

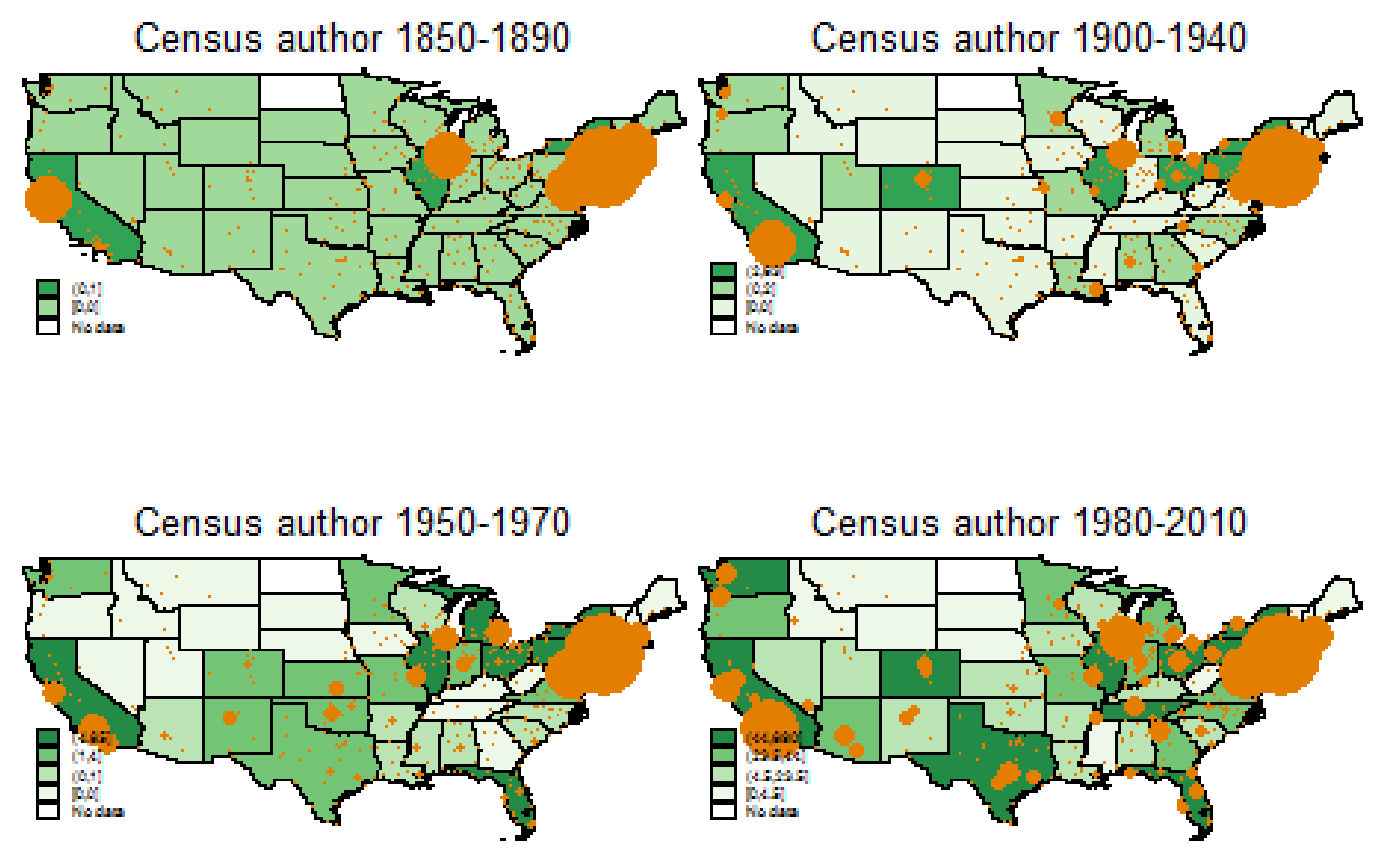

Figure 20: Geographic distribution of authors (Census) 
D.2 Geographic density of creatives
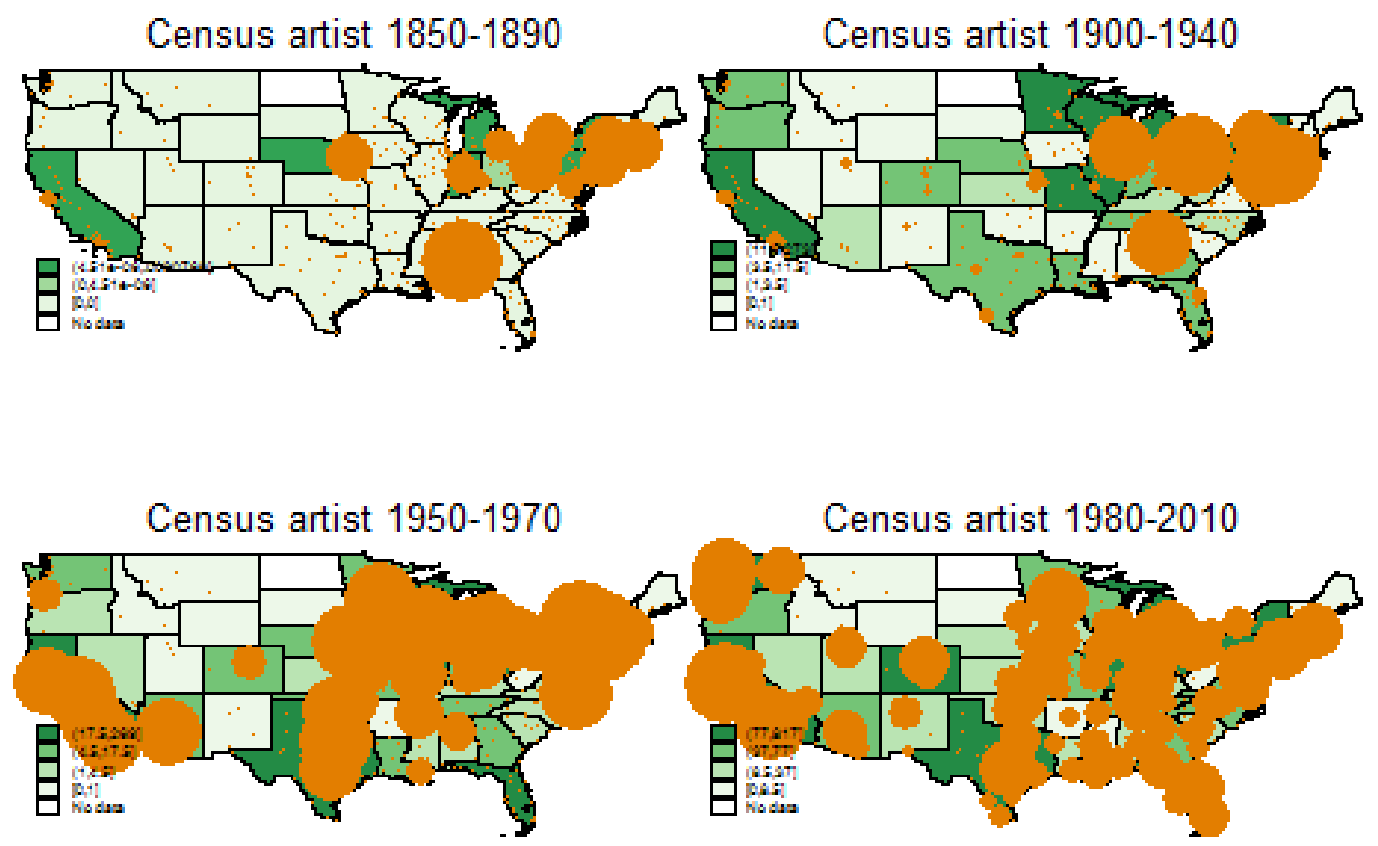

Figure 21: Geographic density of artists (Census) 

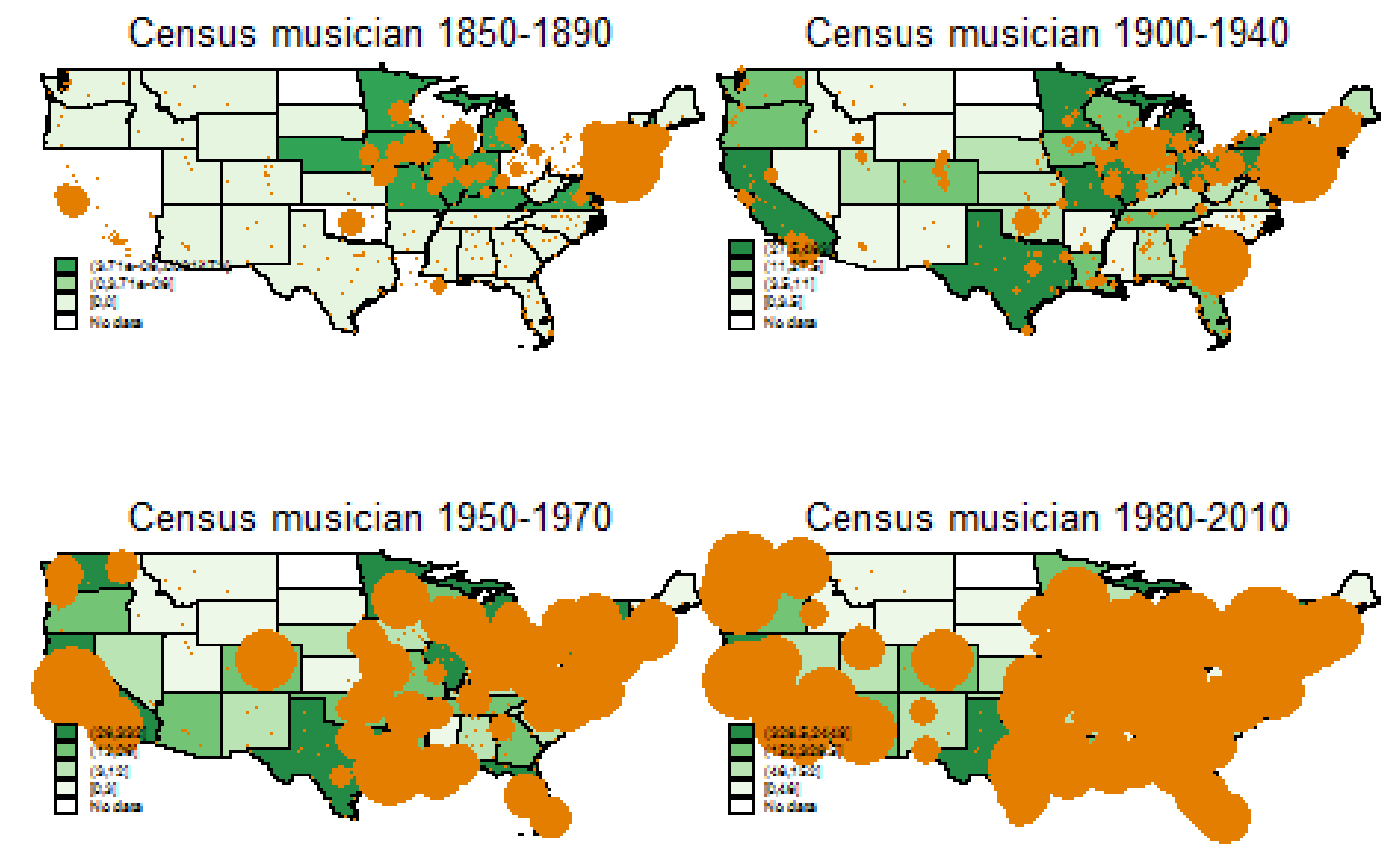

Figure 22: Geographic density of musicians (Census)
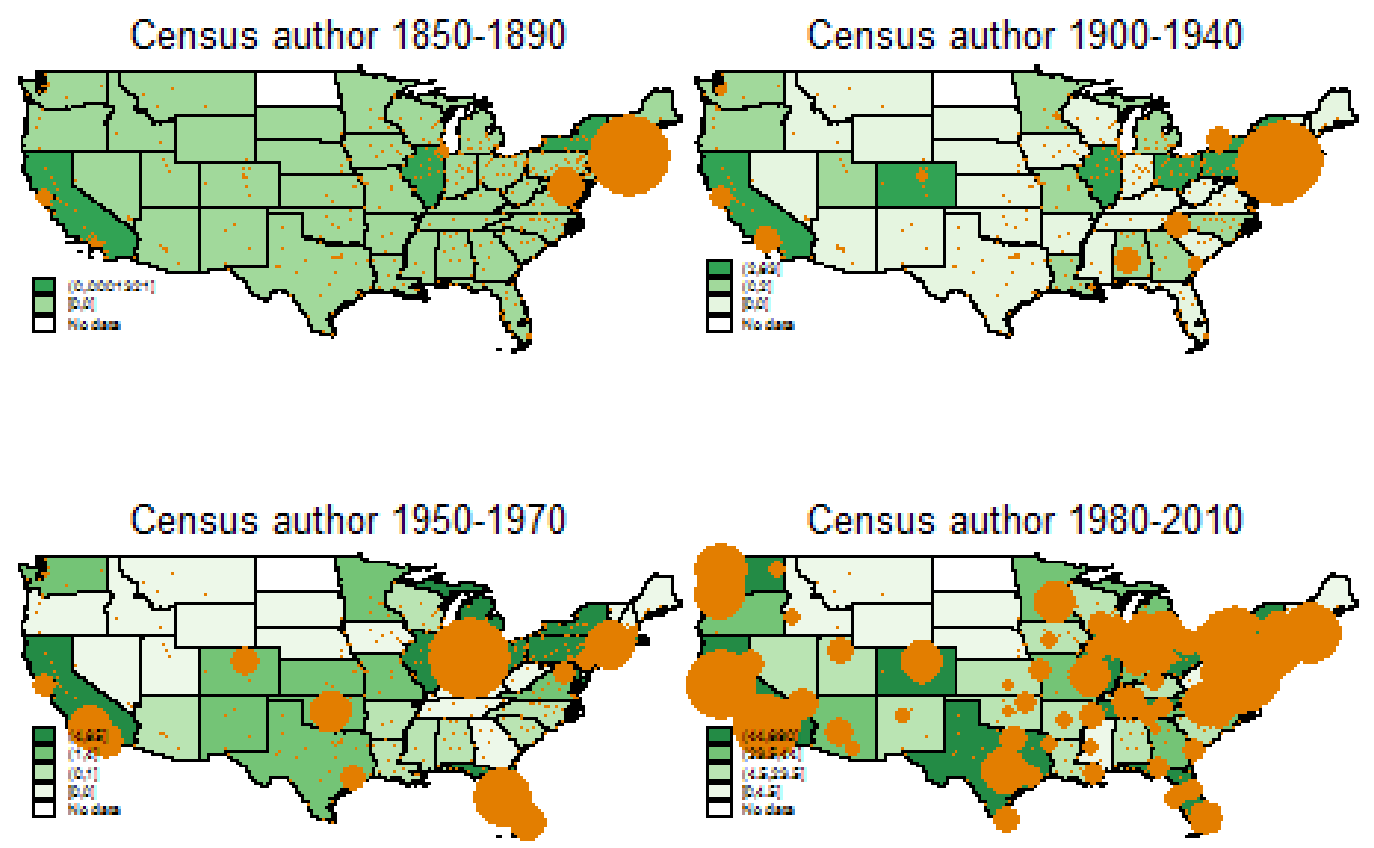

Figure 23: Geographic density of authors (Census) 

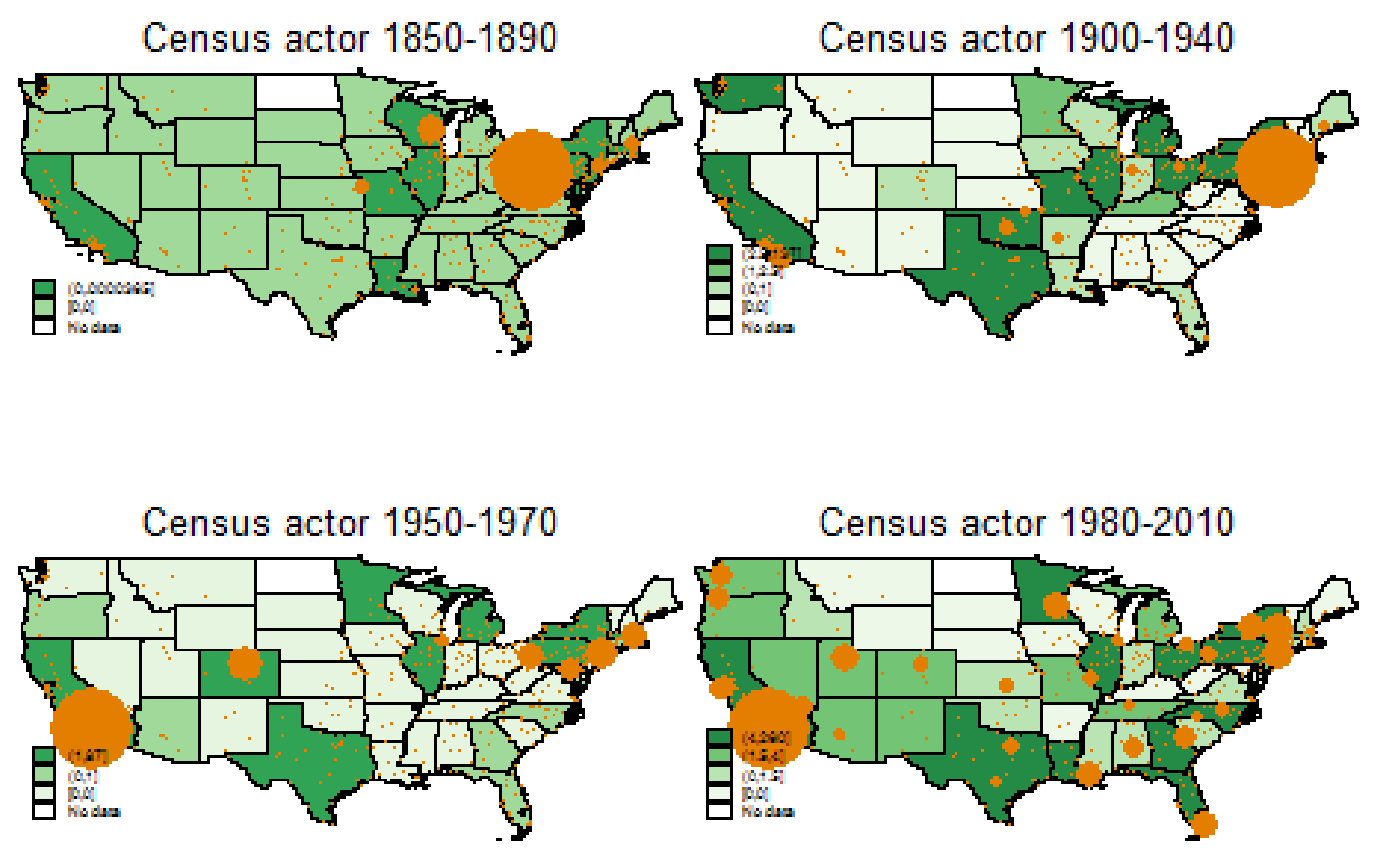

Figure 24: Geographic density of actors (Census) 